\title{
The Stability of Validity Coefficients Over Time: Ackerman's (1988) Model and the General Aptitude Test Battery
}

\author{
James N. Farrell \\ Ernst \& Young LLP
}

\author{
Michael A. McDaniel \\ Virginia Commonwealth University
}

\begin{abstract}
This study examined P. L. Ackerman's (1988) model of skill acquisition within an applied setting. Differences were examined between jobs on the basis of task consistency: changes in performance variability across experience, learning curves, and stability of ability-performance correlations across experience. Results showed the degree of task consistency influenced the shape of learning curves, with jobs composed of primarily consistent tasks improving more rapidly and reaching asymptote sooner. In addition, trends in ability-performance correlations were moderated by the degree of task consistency within a job. Specifically, for jobs with primarily consistent tasks, general cognitive ability best predicted early performance whereas psychomotor ability best predicted later performance. In contrast, general cognitive ability was the strongest predictor across experience for jobs with primarily inconsistent tasks.
\end{abstract}

Applied psychology has paid considerable attention to investigating whether validity coefficients remain stable or fluctuate over time (Ackerman, 1988; Fleishman \& Mumford, 1989a, 1989b; Hulin, Henry, \& Noon, 1990; Murphy, 1989). If validity coefficients are unstable, then a number of concerns arise. How can theorists explain the relationship between abilities and skilled performance? Of what use are ability tests in selecting employees if they do not accurately reflect future performance on the job?

A number of theories have been developed to explain the relationship between abilities and performance during skill acquisition (e.g., Ackerman, 1988; Fleishman \& Mumford, 1989a, 1989b; Hulin et al., 1990). However, only Ackerman's (1988) model of skill acquisition seems capable of reconciling conflicting results that have shown that validity coefficients can both remain stable and decline with practice. Specifically, when the particular ability measured by a test is considered in conjunction with the unique information processing demands of a task, validity coefficients will change in predictable ways across experience (cf. Ackerman, 1988).

Although support for Ackerman's (1988) theory has been shown within experimental studies, little research has examined Ackerman's theory within actual jobs. The purpose of the current research was to examine the various issues surrounding the prediction of performance during skill acquisition using Ackerman's model within an applied setting. The abilities, jobs, and performance that were examined were taken from the General Aptitude Test Battery (GATB) database compiled by the U.S. Employment Service (cf. U.S. Department of Labor, 1980) during the 1970s.

In the following section, the major tenets of Ackerman's (1988) theory of skill acquisition are discussed. In addition, both labora-

James N. Farrell, Professional and Organization Development, Ernst \& Young LLP, Cleveland, Ohio; Michael A. McDaniel, Department of Management, Virginia Commonwealth University.

Correspondence concerning this article should be addressed to James $\mathrm{N}$. Farrell, 2565 Pinebrook Trail, Cuyahoga Falls, Ohio 44223. Electronic mail may be sent to jnfphd@aol.com. tory and applied research is presented as preliminary support for Ackerman's model. Finally, hypotheses concerning variability in performance, learning curves, and the relationship between abilities and performance are articulated.

\section{Ackerman's (1988) Model}

Drawing on previous work in skill acquisition (e.g., Anderson, 1983) and automaticity (e.g., Schneider \& Shiffrin, 1977), Ackerman $(1986,1988)$ proposed a theory of skill acquisition that attempted to explain how task performance can become automatic through practice. A primary prediction made by Ackerman's (1988) theory is that the relationship between abilities (i.e., general cognitive, perceptual speed, and psychomotor) and performance changed as task performance becomes increasingly automatic with practice, an assertion similar to the reorganization of abilities proposed by Woodrow (1946).

In contrast to Henry and Hulin's $(1987,1989)$ assertion that validities will uniformly decrease during skill acquisition, Ackerman (1988) predicted that the linearity and directionality of abilityperformance correlations would depend on the particular ability correlated with task performance. The following is a discussion of the central elements of Ackerman's theory: automaticity, phases of skill acquisition, the use of abilities to predict performance during skill acquisition, moderators of trends in validity coefficients, and learning curves.

\section{Automaticity and Learning}

Ackerman's (1988) theory is based, in part, on Schneider and Shiffrin's (1977) observation that under certain conditions task performance switches from being slow and effortful to being fast and effortless (i.e., automatic; James, 1890). In attempting to explain this transition, Schneider and Shiffrin (1977) noted that the transition from initial learning to skilled performance involved a qualitative shift in information processing. More specifically, it was asserted that the acquisition of skill involved a shift from 
controlled processing to automatic processing (Posner \& Snyder, 1974; Schneider \& Shiffrin, 1977; Shiffrin \& Schneider, 1977).

According to Schneider and Shiffrin (1977), controlled processing results in slow, effortful, and error prone performance; consumes a great deal of attentional resources; and is under conscious control. In regard to skill acquisition, controlled processing occurs when an individual first learns a task or when a task cannot be automatized.

In contrast to controlled processing, automatic processing occurs without intention, is outside of conscious awareness, and consumes few cognitive resources (Posner \& Snyder, 1974). Hasher and Zacks $(1979,1984)$ noted that automatic processes may reflect innate capacities (e.g., frequency counting) or may be the result of extended practice. Of particular interest to Ackerman's (1988) theory is that under certain circumstances (e.g., consistent rules, stimuli, and sequences of actions) practice can result in a transition from controlled to automatic processing (Laberge \& Samuels, 1974; Schneider \& Shiffrin, 1977; Shiffrin \& Schneider, 1977). For example, when people are young, early attempts to walk are time consuming and involve a large number of errors. However, after years of practice, the average person can walk with relatively little effort.

\section{Phases of Skill Acquisition}

Ackerman (1988) noted that previous theory and research supported the idea that as tasks are automatized skill acquisition proceeds through three distinct phases (e.g., Anderson, 1982, 1983; Fitts \& Posner, 1967; Schneider \& Shiffrin, 1977). Phase 1 of skill acquisition corresponds to Anderson's (1983) declarative phase. During this phase, the person's attention is focused on learning instructions and developing strategies for the task. If the material is new, there is a strong demand on attentional resources. Performance at this stage tends to be slow and error prone as the person learns new stimulus-response sequences (i.e., productions; Anderson, 1983). Performance at the declarative phase depends on both general cognitive ability and broad content abilities (e.g., spatial, verbal). However, as skill acquisition proceeds to Phase 2 and on into Phase 3, the need for general cognitive ability declines.

Phase 2 corresponds to Anderson's (1983) knowledge compilation phase, which occurs after a moderate level of task practice. During this phase, individual productions are integrated into sequences of action. With increased practice, performance becomes quicker and more accurate. Furthermore, because the productions are becoming increasingly automatic, there is less demand on attentional resources. During the knowledge compilation phase, demands are placed on an individual's perceptual speed ability. This demand on perceptual speed increases during Phase 1 , peaks during Phase 2, and declines during the latter part of Phase 2 on into Phase 3.

Anderson (1983) termed the final phase of skill acquisition the procedural phase. At this stage of skill acquisition, productions are fully integrated allowing for entire sequences of action to be performed as a single production. In addition, performance at this stage is fast, accurate, and relatively automatic. Because performance is automatic, task performance requires only a slight demand on attentional resources. During the procedural stage, psychomotor abilities play a more important role in task performance than perceptual speed or general cognitive ability.

\section{Predicting Performance With Abilities}

As noted by Ackerman (1988), each phase of skill acquisition differs in the underlying ability that makes the greatest contribution to successful performance. Consequently, if Ackerman's (1988) assumptions are correct, the particular ability that best predicts performance on consistent jobs will change over the course of skill acquisition (see Figure 1). During the first phase, measures of general cognitive ability and general content abilities (e.g., spatial and verbal) will be the best predictors. However, as experience with a task increases, the predictive validity of general cognitive ability will decrease and perceptual speed will be the best predictor of performance. Finally, during the last phase of skill acquisition, the association between perceptual speed and performance will decrease and psychomotor ability will be the best predictor.

\section{Moderators: Consistency and Complexity}

Considerable debate has erupted concerning the stability of validity coefficients over time, with some researchers arguing that they uniformally decrease (e.g., Hulin et al., 1990) and other researchers arguing that they remain constant when artifacts are considered (e.g., Barrett, Caldwell, \& Alexander, 1985). Empirical work has produced mixed results, which only fanned the embers of the "dynamic criteria" debate (cf. Barrett, Caldwell, \& Alexander, 1989). However, recent theoretical and empirical work (e.g., Ackerman, 1986, 1987; Schneider \& Shiffrin, 1977) suggests that validity coefficients may either remain stable or change in predictable ways providing that moderators, such as task consistency and complexity, are taken into account (cf. Ackerman, 1988).

As mentioned previously, tasks that provide consistent rules, stimuli, and sequences of action can be automatized, thus reducing attentional demands. Schneider and Shiffrin (1977) regard these tasks as having conditions that provide "consistent mapping." In contrast, tasks that provide irregular rules, elements, and sequences

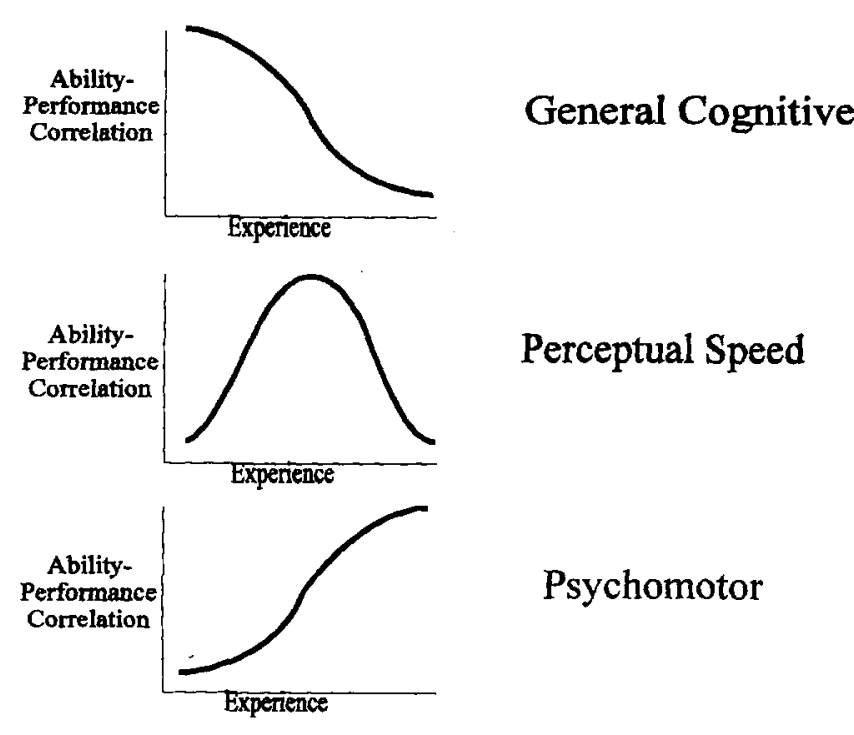

Figure 1. Proposed trends in ability-performance correlations for consistent jobs. 
of action allow for "variable mapping." Under variable mapping conditions, skills cannot be automatized, which results in a constant reliance on controlled processing. The constant use of controlled processing, in turn, results in a continuous demand on attentional resources.

Ackerman (1988) noted that skill acquisition on an inconsistent task does not proceed through the same qualitative shifts as a consistent task. Instead, the transition to Phases 2 and 3 are either slowed or prevented altogether. Furthermore, because skill acquisition remains at Phase 1, demands on cognitive resources will be high. This reliance on attentional resources results in task performance being strongly and consistently related to general and task-relevant broad content abilities (i.e., spatial, verbal). Perceptual speed and psychomotor ability will not show the same pattern of relationships as they do on consistent tasks. Instead, perceptual speed and psychomotor ability will show moderate-to-small stable correlations with task performance (see Figure 2).

In addition to task consistency, task complexity is an important moderator that impacts the skill acquisition process. According to Ackerman (1987), task complexity can involve many elements, including the amount of information provided to the learner, memory load, and sheer number of subtasks. Furthermore, task complexity can impact the attentional demands of a task, the accuracy of performance, and the time to complete a trial (i.e., more time for complex tasks).

Ackerman (1988) noted that one of the difficulties in studying more realistic tasks is that skill acquisition occurs over a longer period of time, making observation more involved. Although not explicitly stated, Ackerman seemed to imply that the increase in task complexity, from laboratory to real-world tasks, will cause the pattern of ability-performance correlations to emerge at a slower rate. In regard to the current study, the pattern of ability-performance correlations found in real-world jobs are likely to emerge over a period of years.

\section{Learning Curves}

In addition to incorporating previous theory and research involving ability-performance relationships and cognitive processing, Ackerman (1987) also integrated work done in the area of learning curves (e.g., Thorndike, 1908) and variability in performance across time (cf. Ackerman, 1987). Ackerman's particular contribution in these areas has been to consider learning curves and variability of performance over time in light of recent devel-

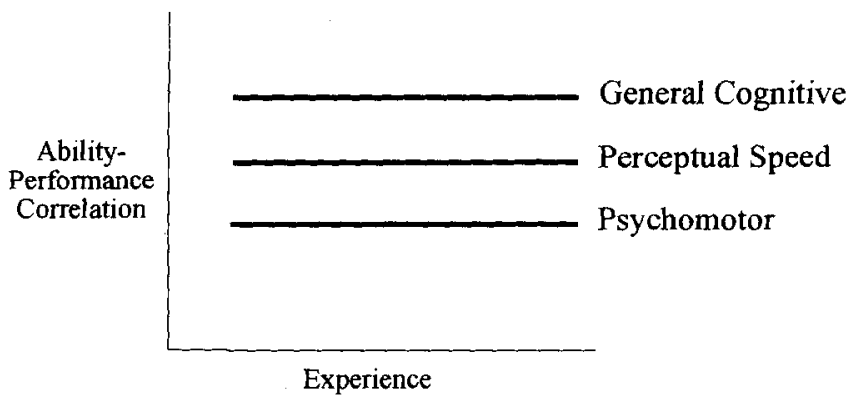

Figure 2. Proposed trends in ability-performance correlations for inconsistent jobs. opments in cognitive psychology (e.g., task consistency; Schneider \& Shiffrin, 1977).

As a result of differences in task consistency, Ackerman, (1986, 1988) proposed that differences could be found in corresponding rates of learning (see Figure 3). For both consistent and inconsistent tasks, there will be an abrupt increase in performance during the initial part of the task. However, with repeated practice, consistent tasks will show rapid improvement until the limits of psychomotor ability are reached. Performance on inconsistent tasks, in contrast, will not improve as rapidly across skill acquisition. Instead, performance stabilizes early, after which performance on the inconsistent task changes less rapidly, as compared to a consistent task (see Figure 3; Ackerman, 1986).

In addition to predictions concerning the shape of the experience-performance curves, Ackerman (1987) noted that changes in variability could be examined. However, the extent to which interindividual difference in variability converge or diverge is a thorny issue that is previously addressed in the skill acquisition literature (cf. Anastasi, 1934). Ackerman (1987) noted that a primary point of concern was the use of both reaction time metrics and attainment metrics in learning research. At issue was the fact that although each metric (i.e., reaction time, attainment) was an inverse of the other, an inverse transformation performed on either metric would not preserve interval level measurement, making comparisons problematic. Furthermore, Ackerman (1987) demonstrated the seemingly paradoxical finding that when a decrease in reaction time (RT) variability is observed, a concomitant increase in attainment variability results.

Although Anastasi (1934) suggested that attainment measures were theoretically more justifiable than time measures, Ackerman (1987) argued that because the focus of his research was primarily cognitive in nature, an examination of variability using the RT metric was more appropriate, as it allowed for a microlevel analysis of task characteristics. The use of attainment measures, in contrast, was probably more viable in practical situations (e.g., industrial settings). Ackerman's (1987) resulting analysis of Kincaid's (1925) data corroborated Kincaid's finding that individual differences converge with practice. Ackerman (1987) cautioned that the convergence of variability was likely due to the consistent nature of the tasks in question. For tasks that are not consistent, variability is likely to remain constant or to increase with time.

\section{Laboratory Evidence}

Results of Ackerman's (1988) laboratory research provided support for the major tenets of his theory. Specifically, the proposed changes in ability-performance correlations for consistent tasks (see Figure 1) has been demonstrated repeatedly (e.g., Ackerman, 1988). Inconsistent tasks, however, have not shown this pattern.

Ackerman's research involving fairly simple laboratory tasks (e.g., Ackerman, 1988) provided compelling evidence that the relationship between abilities and performance could change with practice. However, some researchers have questioned the generalizability of Ackerman's early work arguing that the tasks used had short time frames (e.g., $5 \mathrm{~min}$ ) and bore little resemblance to real-world tasks (e.g., Barrett et al., 1989). To extend research results to tasks that approximated actual jobs, recent studies have examined the tenets of Ackerman's (1988) theory by using air 


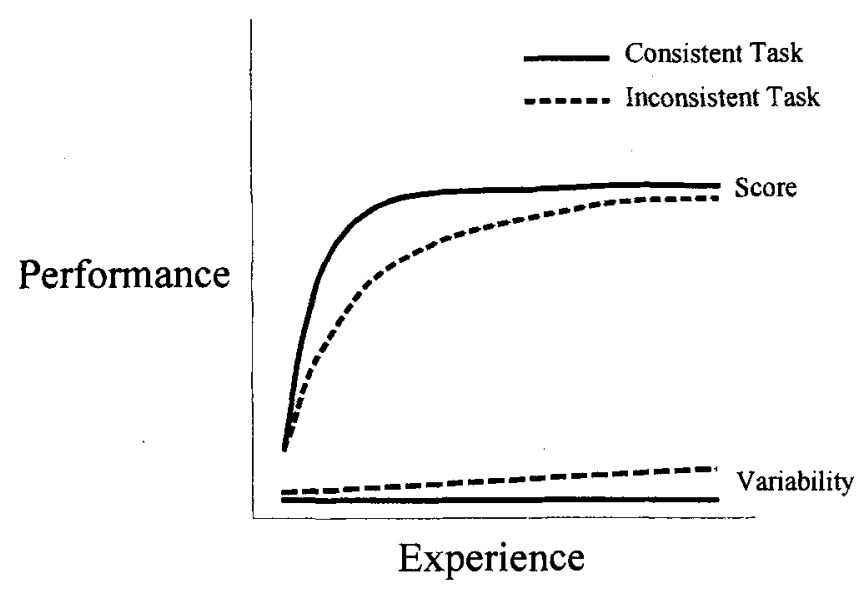

Figure 3. Proposed trends in performance and performance variability for both consistent and inconsistent jobs.

traffic controller simulations that had both consistent (e.g., Kanfer \& Ackerman, 1989) and inconsistent (e.g., Ackerman, 1992) characteristics.

Kanfer and Ackerman (1989) investigated ability performance relations for a complex-consistent air traffic controller (ATC) simulation. The ATC is a computer-based simulation that involves assigning runways at a simulated airport. Participants were given 5 $\mathrm{hr}$ of practice and were rated on a number of dependent variables, such as number of planes landed and number of errors. Consistent with previous findings for consistent tasks (e.g., Ackerman, 1988), the relationship between abilities and performance changed over the course of skill acquisition. General cognitive ability showed the highest correlation with initial performance, perceptual speed showed the highest correlation with intermediate performance, and psychomotor showed the highest correlation with final performance.

Attempting to extend previous findings to an inconsistent simulation, Ackerman (1992) used the Terminal Radar Approach Control Simulation (TRACON) in assessing ability-performance relations. Participants were given $15 \mathrm{hr}$ of practice and were assessed on overall performance as well as on variables such as number of flights accepted, number of arrivals/departures, and number of errors. Results demonstrated that overall performance was consistently associated with general and broad content abilities (i.e., spatial), whereas perceptual and psychomotor abilities showed stable but lower correlations with performance over the course of practice. Although results supported predictions for inconsistent tasks (cf. Ackerman, 1988), Ackerman (1992) noted that consistent task components did produce changes in abilityperformance relations shown previously (e.g., Kanfer \& Ackerman, 1989).

\section{Research in Industrial Settings}

To date, there has been no applied study that directly tested all aspects of Ackerman's (1988) theory. However, numerous studies have been conducted that either directly or indirectly tested parts of the theory. In general, this literature has been supportive of the principles of skill acquisition proposed by Ackerman (1988).

\section{Learning Curves}

Although the shape of the learning curve has been well documented, applied research has contributed to learning research by examining learning curves over a wide variety of jobs and extended periods of time (e.g., McDaniel, 1986) and by examining the impact of moderators on experience curves (Schmidt, Hunter, Outerbridge, \& Goff, 1988).

Ability and experience curves. McDaniel (1986) examined the shape of experience-performance curves over a 20-year period using a cross-sectional design. Of particular interest, McDaniel (1986) examined the moderating influence of various levels of ability on the shape of learning curves. Using the GATB database, a wide selection of employees were subdivided into three groups according to level of general cognitive ability, and then differences in learning curves were examined. In contrast to Thorndike's (1908, 1914) finding that individual differences diverge with experience, McDaniel (1986) found that differences between the three ability groups remained constant, a finding that may have resulted from using supervisor ratings as opposed to output as a measure of job performance (e.g., Thorndike, 1908).

Additional research corroborated the findings of McDaniel (1986) using a military sample and the Armed Forces Qualification Test (AFQT; Schmidt et al., 1988). Schmidt et al. (1988) tested three hypotheses concerning the impact of individual differences on the relationship between experience and performance (i.e., supervisor ratings) over time: convergence hypothesis, divergence hypothesis, and noninteractive hypothesis. Consistent with the results of McDaniel (1986), Schmidt et al. (1988) found that differences in experience-performance curves for various levels of ability did not change appreciably over time. Consequently, Schmidt et al. (1988) concluded that their results supported a noninteractive hypothesis of learning curves for groups differing in levels of ability.

Complexity and learning curves. Several studies concerning the impact of levels of complexity on learning curves have emerged out of a line of research that examined moderators of the age-performance relationship (e.g., McEvoy \& Cascio, 1989; Waldman \& Avolio, 1986). Specifically, the work of these researchers examined whether job type moderated the relationship between age and performance. Results from these studies provided mixed evidence, with Waldman and Avolio (1986) finding a moderating effect for job type whereas McEvoy and Cascio (1989) finding no such moderating effect.

In addition to an examination of moderators of the age-performance relationship, this line of research has examined the impact of moderators on the experience-performance relationship (e.g., Avolio, Waldman, \& McDaniel, 1990), as experience tends to be a stronger predictor of performance than age (Giniger, Dispenzieri, \& Eisenberg, 1983; McDaniel, Schmidt, \& Hunter, 1988; Schwab \& Heneman, 1977). The focus of this research was to uncover differences in plateauing effects of experience-performance curves for jobs differing in levels of complexity.

Using a cross-sectional design, Avolio et al. (1990) examined experience-performance curves for a variety of jobs (i.e., clerical, craft, and service) over a 20-year period. Although the usual learning curve was observed for most jobs (i.e., negatively accelerated, monotonically increasing), an inverse $U$ curve was observed for lower clerical jobs. Avolio et al. (1990) concluded that 
the lower complexity of the lower clerical jobs may have resulted in reduced challenge and motivation and, consequently, performance. Another possibility is that over time higher ability participants move to higher level positions, resulting in lower performance ratings due to the lower ability individuals that remain behind.

\section{Ability-Performance Correlations}

Recent research has not seen a direct use of Ackerman's (1988) theory in an industrial setting. However, Ackerman and Kanfer (1993) have cross-validated the ATC task used in Ackerman's previous work (e.g., Ackerman, 1992) on a sample of Federal Aviation Administration (FAA) ATC trainees. Consistent with his theory (Ackerman, 1988), Ackerman found that due to the inconsistent nature of the ATC task, broad and general content abilities were most predictive. However, because Ackerman and Kanfer's (1993) work was the initial part of a long-term study, ability-performance correlations were not reported across time.

Other research has examined differences in validity coefficients using a longitudinal design, but either the variables assessed were not relevant to the current paper or patterns of correlations simply were not reported (e.g., Bray \& Howard, 1983; Kaufman, 1972, 1974). For example, Kaufman $(1972,1974)$ examined the impact of early job knowledge (i.e., engineering knowledge) and job challenge on later currency (i.e., patents) and job performance. Although it was found that early challenge was related to later performance and that early job knowledge was related to currency, no attempt was made to examine the relationship between a battery of cognitive tests and job performance.

In contrast to the work conducted by Kaufman $(1972,1974)$, Bray and Howard (1983) conducted a longitudinal study for AT\&T that examined the relationship between performance of managers in an assessment center and later job success. As part of the assessment center, a host of individual difference variables were measured including cognitive ability (i.e., School and College Abilities Test or SCAT), personality, motivation, and performance on business simulations. Although patterns of correlations were not reported, Bray and Howard (1983) did find that scores on the SCAT were the best predictor of managerial success, a finding consistent with the work of Ghiselli (1973).

Additional work in the area of industrial/organizational psychology has examined ability-performance correlations using crosssectional designs (e.g., Schmidt et al., 1988). For example, Pearlman, Schmidt, and Hunter (1980) used validity generalization procedures (cf. Hunter, Schmidt, \& Jackson, 1982) to examine the relationship between abilities and both training and job performance (i.e., supervisor ratings). In addition to finding that the relationship between training and job criteria was greater than previously believed, a finding perhaps attributable to the use of corrections for artifacts, Pearlman et al. (1980) found a pattern of ability-performance correlations similar to those reported by Ghiselli $(1966,1973)$ : General cognitive was the best predictor of both training and job performance, but the difference between validities involving general cognitive ability and perceptual ability were reduced from training to job performance.

Research by McDaniel (1986) has examined the stability of ability-performance relationships using the GATB database. Using general cognitive ability as a predictor and supervisor ratings as criteria, McDaniel (1986) showed that ability-performance correlations for a variety of jobs declined over the first 10 years of experience. However, later work by Schmidt et al. (1988) using a military sample and the AFQT found that, for the first 5 years at least, general cognitive ability remained a stable predictor of job performance.

The work of Schmidt and colleagues (e.g., McDaniel, 1986) has demonstrated that when validity coefficients are examined over an extended period of time (e.g., 10 years) validities can decline. However, the focus of this research has been on general cognitive ability as a predictor, perhaps due to the assertion by these researchers that general cognitive ability is presumed to be the most valid predictor for all jobs (cf. Hunter \& Hunter, 1984).

\section{Consistency as a Moderator}

Although consistency per se has not been examined within industrial settings, consistency may have been studied under the guise of job complexity (e.g., Hunter, 1983a). The fact that research variables have not been specifically termed "task consistency" or "resource dependence" (cf. Ackerman, 1988; Anderson, 1983) is undoubtedly due to the liberal definitions of task complexity that have surfaced in the skill acquisition literature (cf. Snow \& Lohman, 1984). Of the four definitions examined by Snow and Lohman (1984), the fourth definition involves processes that organize, adapt, and monitor sequences of responses that are arranged into a performance program for responding to a task or test. This description of complexity is consistent with definitions of information-processing requirements related to a task's consistency or resource dependence (cf. Ackerman, 1988; Anderson, 1983). Therefore, research that defines task complexity according to Snow and Lohman (1984) is arguably measuring task consistency.

Research within industrial settings has used task complexity to examine a number of issues. McDaniel et al. (1988) examined the moderating effect of complexity on experience-performance correlations, finding that experience is a better predictor for low complexity jobs. Other research has attempted to relate mental requirements of jobs (e.g., complexity) to motivational attributes of jobs, arguing that mentally challenging (e.g., complex) jobs may be more motivational in the long term (cf. Campion, 1989). Of importance to the current paper is research that has specifically measured the moderating impact that job complexity has on test validities involving abilities (i.e., general cognitive, perceptual speed, and psychomotor) and job performance (e.g., supervisor ratings).

Schmidt, Hunter, and Pearlman (1981) examined the moderating effect of the Dictionary of Occupational Titles (DOT; U.S. Department of Labor, 1977) classification on test validities involving abilities (i.e., general cognitive and perceptual speed) and supervisor ratings. Results indicated that the moderating effect of job classification was small or nonexistent, resulting in the conclusion that gross job classification did not moderate test validities. However, Schmidt et al. (1981) did note that the lack of moderating effect for job classification may have been due to its general nature and that more specific measures, which address the information-processing and problem-solving requirements of jobs, might prove more useful as moderators. 
More recent studies have examined the moderating effect of more specific measures of job complexity (e.g., Gutenberg, Arvey, Osburn, \& Jeanneret, 1983; Hunter, 1983a). Using the Position Analysis Questionnaire (PAQ; McCormick, Jeanneret, \& Mecham, 1972), Gutenberg et al. (1983) were able to demonstrate that the unique information-processing requirement of a job moderated test validities. Specifically, when the information-processing dimension of the PAQ was used to moderate test validities, results produced positive correlations for cognitive abilities (i.e., general cognitive, verbal, and numerical) and negative correlations for psychomotor ability (i.e., finger and manual measures). In other words, validities for cognitive ability measures were higher for more cognitively demanding jobs, whereas validities for psychomotor measures were higher for less cognitively demanding jobs.

Using a different measure of complexity, Hunter (1983a) and Gandy (1986) were able to show that complexity moderates validity coefficients. The particular measure used by Hunter was a five-level scale derived from the Data and Things dimension of the DOT (cf. Fine, 1955). In addition to examining job proficiency (i.e., supervisor ratings), Hunter was able to assess the moderating impact of job complexity on ability-training proficiency correlations. For training criteria, validities involving general cognitive ability (i.e., general cognitive, verbal, numerical) were not moderated by complexity, displaying high correlations for all levels of complexity. Psychomotor abilities, in contrast, were moderated by complexity, showing decreases in validities with increasing levels of job complexity.

In terms of job proficiency, Hunter (1983a) and Gandy (1986) both found a moderating effect for complexity on the ability-performance relationship. Complexity moderated the validities for both cognitive and psychomotor tests: For cognitive ability tests, validities increased with increases in complexity; for psychomotor tests, validities decreased with increases in complexity. The pattern of results observed for training and job proficiency are consistent with previous findings (e.g., Ghiselli, 1966, 1973) that there were differences in validities based on complexity and differential influences of abilities based on training versus job proficiency criteria.

\section{Hypotheses}

On the basis of Ackerman's (1988) theory, the following hypotheses are proposed.

\section{Hypothesis 1: Rate of Learning}

Both jobs with primarily consistent tasks and jobs with primarily inconsistent tasks will show the usual learning curve found in previous research. However, rate of learning will differ based upon the proportion of consistent/inconsistent tasks, with jobs containing primarily consistent tasks producing a curve with more rapid improvement that reaches asymptote sooner (see Figure 3 ).

\section{Hypothesis 2: Variability in Performance}

Because the performance data are supervisor ratings, it is difficult to make theoretical predictions based on previous work involving RT or output measures (cf. Ackerman, 1987). However, research in industrial/organizational psychology does provide some insight into the impact of experience on variability in performance (McDaniel, 1986; Schmidt et al., 1988). Although these researchers did not investigate variability in terms of standard deviation, they did look at variability in performance in much the same way as Thorndike (1908), which was to divide groups according to general cognitive ability and observe whether performance ratings converged or diverged. However, unlike Thorndike (1908), Schmidt et al. (1988) found that individual differences between ability groups remained constant for the first 5 years of experience. Schmidt et al. (1988) suggested that these results were due to the moderate complexity of the jobs observed and that for high complexity jobs differences between ability groups would diverge.

On the basis of the results of previous research (McDaniel, 1986; Schmidt et al., 1988), it is proposed that trends in variability of performance across experience will differ on the basis of the proportion of consistent/inconsistent tasks within a job. Variability in performance for jobs with primarily consistent tasks will remain constant over time, whereas variability for inconsistent jobs will increase over time (see Figure 3 ).

\section{Hypothesis 3: Ability-Performance Relationships Across Skill Acquisition}

The relationship between abilities and performance appraisal ratings across skill acquisition will differ between jobs with primarily consistent tasks and jobs with primarily inconsistent tasks. For jobs with primarily consistent tasks, the pattern of associations will change in accordance with Ackerman's predictions (see Figure 1). For jobs with primarily inconsistent tasks, general cognitive ability will show the highest association with performance across all levels of experience, whereas perceptual speed and psychomotor ability will show small stable associations across experience (see Figure 2).

\section{Method}

\section{Data Description}

Data for the current study were taken from the GATB database compiled by the U.S. Employment Service during the 1970s (U.S. Department of Labor, 1980). The database provides information on personal characteristics, abilities, jobs, and work performance for over 24,000 individuals. Jobs are classified according to their codes in the DOT (Fine, 1955; Studdiford, 1951; U.S. Department of Labor, 1977). The database includes a wide range of jobs, such as professional-managerial, clerical, sales, and machine trades.

\section{Measures}

GATB tests and composites. The GATB consists of 11 tests that are reported to measure nine aptitudes (cf. Hartigan \& Wigdor, 1989): intelligence, verbal aptitude, numerical aptitude, spatial aptitude, form perception, clerical perception, motor coordination, finger dexterity, and manual dexterity.

Abilities and composites for the current study. Hunter (1983b) applied a confirmatory factor analysis to the GATB tests and discovered that three main factors emerged: Cognitive (GVN), Perceptual (SPQ), and Psychomotor (KFM). Additional literature in the area of skill acquisition seems to corroborate the use of Hunter's three construct taxonomy for 
measures (cf. Ackerman, 1988). For example, in Ackerman's work, trends in ability performance relationships are examined with the same three primary ability measures: general cognitive ability, perceptual speed, and psychomotor ability. Therefore, Hunter's taxonomy of ability measures was used in the current research.

Because the cognitive ability measure in the current study is likely to be correlated with the perceptual speed and psychomotor ability measures, the variance attributable to cognitive ability (i.e., GVN) was partialled out of the perceptual speed measure and psychomotor ability measure. The partialling out of general cognitive ability should produce more accurate estimates of the latent variables, a concern that Ackerman (1988) addressed through the use of factor analytic techniques.

Job performance. The criterion used in the current study was performance ratings by supervisors. The actual measure was a composite of two performance ratings given 1 week apart by the same supervisor. The scales used varied along six dimensions (i.e., quantity, quality, accuracy, job knowledge, efficiency, and overall performance), with supervisors rating each employee on a 5-point scale. An examination of test-retest reliability for performance ratings in the GATB dataset has shown a reliability estimate of .86 (cf. Hartigan \& Wigdor, 1989). Although interrater reliabilities are not available for the current dataset, research has estimated the upper bound of interrater reliability for performance appraisal ratings to be around .60 (King, Hunter, \& Schmidt, 1980; Rothstein, 1990; Viswesvaran, Ones, \& Schmidt, 1995).

Job consistency. Applied research in the area of industrial/organizational psychology has not produced a scale that directly addresses task consistency or resource dependence. Therefore, because applied research may have subsumed consistency under the rubric of task complexity, Hunter's (1983a) complexity scale was used to measure task consistency. This scale was derived from the Data and Things dimensions (Fine, 1955) provided in the DOT (U.S. Department of Labor, 1977) and is divided into five levels of job complexity, based on the information-processing requirements of each task (cf. Gandy, 1986). However, because Gandy (1986) questioned the reliability of the Things dimension, only the Data dimension was used in the current study.

Using complexity ratings as a measure of consistency raises some concerns regarding the construct validity of the current study's consistency measures. First, it may be the case that very few jobs have a majority of consistent tasks. To compensate for this, an extreme groups design has been used with the complexity measure; the consistent group is comprised of jobs with a DOT data rating of 6 and the inconsistent group is comprised of a combination of jobs with DOT data ratings of 1 and 2 .

The second issue involved in using complexity as a measure of consistency is whether the complexity measure is actually assessing the consistency of jobs (e.g., construct validity). To provide additional supporting evidence, a second measure of consistency, Tolerance for Repetition (U.S. Department of Labor, 1980), was also used to conduct the analyses. The rating of tolerance is a dichotomous item that estimates the level of tolerance for repetition an employee must have to adequately perform a particular job.

Job experience. Because it is likely that individuals acquire job knowledge and skills across organizations, the pattern of skill acquisition, described by Ackerman (1988), is likely to emerge across organizations as well. Therefore, the current research used the measure of total job experience. Total job experience was assessed with an item that had workers indicate their experience with their current occupation (i.e., months and years) with both present and previous employers.

\section{Analyses}

The analyses focused on comparing trends in the data (i.e., mean performance ratings, standard deviation of performance ratings, and ability-performance correlations) against those predicted by Ackerman's (1988) research. Because of the constant reduction in sample sizes across levels of experience could produce unwanted variability in correlations, experience levels were determined as follows: Years 1-5 were divided into 6-month intervals, and Years 5-10 were divided into 12-month intervals, This resulted in 15 experience groups. The specific analyses conducted for each of the hypotheses are described below.

Testing Hypotheses 1 and 2: Learning curves. This analysis involved the examination of curves formed by plotting mean performance rating and standard deviation of performance across experience. The analysis began by dividing each of the 15 experience groups by consistency, using both the complexity and tolerance for repetition measures. For each of the 15 consistency subgroups, a mean and standard deviation of performance ratings was generated. Next, the trends in means and standard deviations were plotted using the regression line that best fit the data. This procedure involved regressing the observed dependent variables (i.e., means and standard deviations) onto two independent variables (i.e., experience and experience squared), calculating an estimate of the least squares regression line, calculating a predicted value for each experience group, and then plotting the predicted values. Finally, the generated plots were visually compared against the trends predicted in the hypotheses.

Testing Hypothesis 3: Trends in correlations across experience. This analysis involved the examination of curves formed by plotting abilityperformance correlations across experience. The analysis began by dividing each of the 15 experience groups by consistency, using both the complexity and tolerance for repetition measures. For each of the 15 consistency subgroups, three correlations were calculated: general cognitive-performance rating, perceptual speed-performance rating, and psychomotor ability-performance rating.

Correlations for each of the experience groups were corrected for both range restriction and criterion unreliability. Range restriction was corrected using the formula recommended by Hunter et al. (1982). This correction first requires the calculation of restricted and unrestricted standard deviations for each of the subtests, as well as the intercorrelation between the subtests for each composite measure. Next, the restricted and unrestricted standard deviations for the subtests, as well as their intercorrelations, were used to calculate the restricted and unrestricted standard deviations for the composite measures, as recommended by McNemar (1962). Finally, the restricted and unrestricted values were used to correct the correlations for range restriction using the formula specified by Hunter et al. (1982).

Once the correlations were corrected for range restriction, a correction was made for average criterion unreliability (Hunter et al., 1982). This involved multiplying each correlation by the inverse of the square root of the average criterion unreliability. In this case, average criterion unreliability was estimated at .60, as recommended by Pearlman et al. (1980).

After the correlations were corrected, the trends in the ability-performance correlations were plotted using the regression line that best fit the data. As with the testing of Hypotheses 1 and 2 , this procedure involved regressing the observed dependent variables (i.e., ability-performance correlations) onto two independent variables (i.e., experience and experience squared), calculating an estimate of the least squares regression line, calculating a predicted value for each experience group, and then plotting the predicted values. Finally, the generated plots were visually compared against the trends predicted in the hypotheses.

\section{Results}

Descriptive statistics for the major variables in the current study are reported in Table 1 . An examination of means, ranges, and standard deviations showed that values were in expected ranges. The three composite ability measures showed the typical positive manifold for the nonresidualized sample. The residualized sample, in contrast, showed no correlation between the residualized variables and general cognitive ability, as expected. However, the residualized perceptual speed and psychomotor measures were still moderately correlated. Without exception, all ability composites 
Table 1

Descriptive Statistics

\begin{tabular}{|c|c|c|c|c|c|c|c|c|c|c|}
\hline Measure & $M$ & Range & $S D$ & 1 & 2 & 3 & 4 & 5 & 6 & 7 \\
\hline 1. General cognitive & 188.13 & $92-327$ & 33.17 & - & $.69 * *$ & 0 & $.38 * *$ & 0 & $-.05 * *$ & $.21 * *$ \\
\hline 2. Perceptual speed & 215.43 & $76-383$ & 37.36 & & - & $.65^{* *}$ & $.56^{* *}$ & $.32 * *$ & $-.22^{* *}$ & $.18^{* *}$ \\
\hline $\begin{array}{l}\text { 3. residual) } \\
\text { (resed }\end{array}$ & 0 & $-114-147$ & 33.33 & & & - & $.38^{* *}$ & $.41 * *$ & $-.22 * *$ & $.03^{* *}$ \\
\hline 4. Psychomotor & 305.57 & $71-531$ & 51.43 & & & & - & $.92 * *$ & $-.26 * *$ & $.13^{* *}$ \\
\hline $\begin{array}{l}\text { 5. Psychomotor } \\
\text { (residual) }\end{array}$ & 0 & $-229-210$ & 47.54 & & & & -- & $-.27 * *$ & $.06^{* *}$ & \\
\hline $\begin{array}{l}\text { 6. Total job experience } \\
\text { (months) }\end{array}$ & 74.87 & $1-624$ & 82.03 & & & & & & - & $.18^{* *}$ \\
\hline 7. Supervisor rating & 43.41 & $12-60$ & 8.10 & & & & & & & - \\
\hline
\end{tabular}

Note. $N=24,049$.

${ }^{* *} p=.01$.

showed significant positive correlations with performance ratings. An examination of the relationship between the composite ability measures and experience showed that all correlations were negative and significant.

\section{Learning Curves}

Mean performance. Mean performance ratings, for the analysis using complexity as consistency, are reported in Table 2. A graph of the regression lines are displayed in Figure 4. The curves produced by both the consistent and inconsistent jobs showed that mean performance ratings increase with experience. However, only the consistent sample produced a negatively accelerated curve, as predicted by the hypotheses. A comparison of the curves showed that mean performance for consistent jobs increased more rapidly and reached asymptote sooner, in comparison to the inconsistent sample.

Mean performance ratings, for the analysis involving tolerance for repetition, are reported in Table 3. A graph of the regression lines are displayed in Figure 5. Both curves show a negatively accelerated, monotonically increasing function. In addition, the

Table 2

Supervisor Ratings: Sample Sizes, Means, and Standard Deviations, With Complexity as the Measure of Consistency

\begin{tabular}{cccccccc}
\hline & \multicolumn{3}{c}{ Consistent jobs } & & \multicolumn{3}{c}{ Inconsistent jobs } \\
\cline { 2 - 3 } \cline { 6 - 7 } $\begin{array}{c}\text { Experience } \\
\text { (months) }\end{array}$ & $n$ & $M$ & $S D$ & & & $M$ & $S D$ \\
\hline & & & & & & & \\
$1-6$ & 905 & 39.05 & 7.72 & 34 & 36.09 & 11.96 \\
$7-12$ & 904 & 40.35 & 7.67 & 320 & 41.18 & 8.99 \\
$13-18$ & 594 & 40.55 & 7.97 & 167 & 40.92 & 8.71 \\
$19-24$ & 534 & 41.99 & 8.02 & 173 & 40.61 & 6.86 \\
$25-30$ & 393 & 42.54 & 7.99 & 169 & 40.44 & 7.26 \\
$31-36$ & 455 & 42.88 & 8.21 & 193 & 40.91 & 7.10 \\
$37-42$ & 313 & 43.60 & 7.50 & 147 & 42.55 & 8.10 \\
$43-48$ & 319 & 43.65 & 7.57 & 180 & 42.57 & 7.78 \\
$49-54$ & 220 & 42.33 & 7.75 & 116 & 43.55 & 7.69 \\
$55-60$ & 293 & 43.97 & 7.78 & 136 & 43.17 & 7.93 \\
$61-72$ & 442 & 44.04 & 8.32 & 235 & 43.18 & 7.41 \\
$73-84$ & 367 & 43.90 & 8.07 & 196 & 43.84 & 8.45 \\
$85-96$ & 300 & 44.48 & 8.08 & 186 & 43.72 & 7.40 \\
$97-108$ & 203 & 44.63 & 7.75 & 142 & 44.78 & 7.33 \\
$109-120$ & 207 & 44.58 & 7.68 & 161 & 44.53 & 8.12 \\
\hline
\end{tabular}

curve produced by the consistent jobs increased more rapidly and reached asymptote sooner, in comparison to the curve produced by the mean performance ratings for inconsistent jobs.

A comparison of results, produced by the two different consistency measures, indicated that when jobs are separated according to task consistency differences in learning curves emerge: Learning curves for the consistent sample increased more rapidly and reached asymptote sooner in comparison to the curves produced by the inconsistent sample of jobs.

Standard deviation of performance. Standard deviation of performance ratings for the analysis using complexity as consistency are reported in Table 2. Figure 6 displays the graphs of the regression lines that provided the best fit to the data. The curve produced by the consistent sample shows a slight increase in variability over experience. The curve produced by the inconsistent jobs, in contrast, produced a quadratic function with values initially decreasing and then increasing across experience. A comparison of the two curves shows that separating the jobs into consistency groups results in different trends in variability across experience.

For the inconsistent sample, standard deviation of performance ratings are reported in Table 3. Figure 7 displays plots of the regression lines that provided the best fit to the data. For the consistent sample, the shape of the curve is flat, with a slight decrease from 55-120 months. The curve produced by the inconsistent sample shows a slight quadratic function, initially decreasing with experience and then increasing.

Results of the analyses involving trends in variability across experience showed that when jobs are separated according to consistency, different functions tend to emerge. Specifically, consistent jobs produce monotonically decreasing and negatively accelerating functions, whereas inconsistent jobs show a quadratic function, initially increasing and then decreasing.

\section{Ability Performance Correlations}

Correlations. Tables 4 and 5 show the ability-performance correlations for the analysis that used complexity as the measure of consistency. For the most part, correlations were positive, the exception being a few negative correlations produced in the inconsistent sample of jobs by perceptual speed and psychomotor ability. 


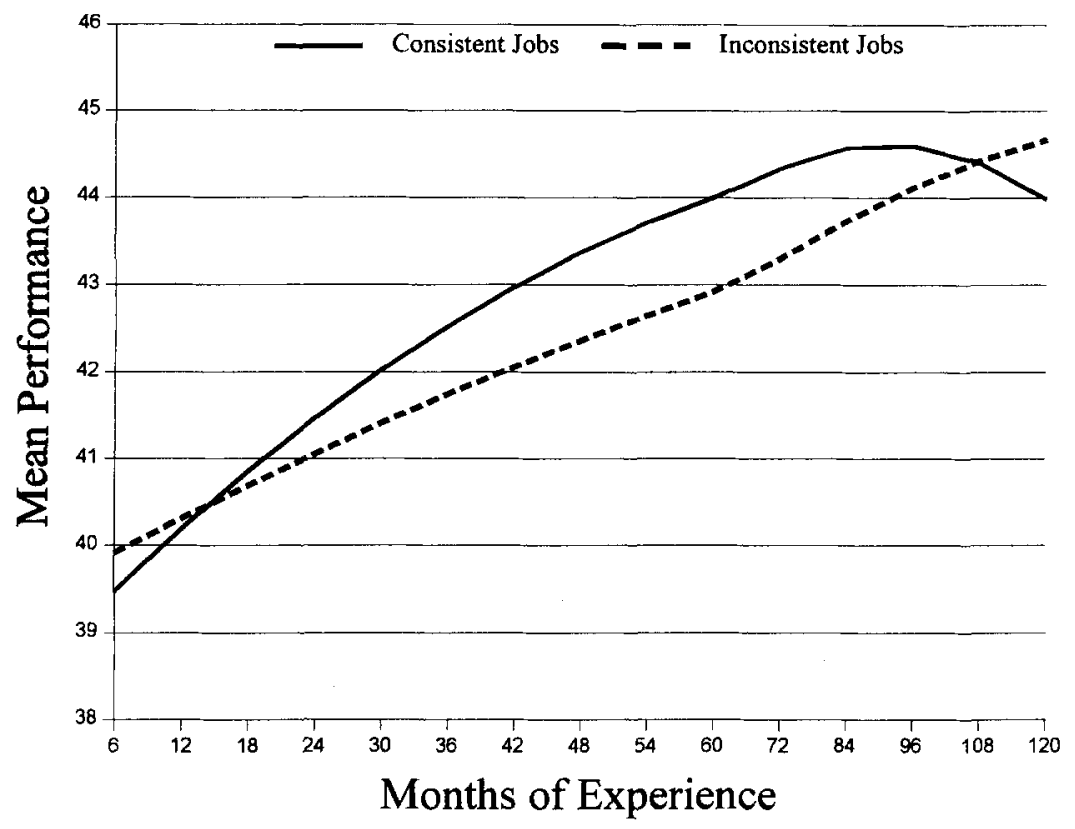

Figure 4. Trends in mean performance ratings for both consistent and inconsistent jobs, with complexity as the measure of consistency. The least squares equations for each of the curves are as follows: consistent jobs, $R_{x y}$ $=.80$ (experience) -.03 (experience) $)^{2}+38.69$; inconsistent jobs, $R_{x y}=.42$ (experience) -.008 (experience $)^{2}+39.49$.

Results involving the use of tolerance for repetition as consistency mirrored those that used complexity (Tables 6 and 7). In general, all correlations were positive; the exception was a few negative correlations in the inconsistent sample involving perceptual speed and psychomotor ability.

\section{Trends in Ability-Performance Correlations}

Consistent jobs. Figure 8 shows the plots of the regression lines that best fit the sample of ability-performance correlations

Table 3

Supervisor Ratings: Sample Sizes, Means, and Standard Deviations, With Tolerance for Repetition as the Measure of Consistency

\begin{tabular}{|c|c|c|c|c|c|c|}
\hline \multirow{2}{*}{$\begin{array}{l}\text { Experience } \\
\text { (months) }\end{array}$} & \multicolumn{3}{|c|}{ Consistent jobs } & \multicolumn{3}{|c|}{ Inconsistent jobs } \\
\hline & $n$ & $M$ & $S D$ & $n$ & $M$ & $S D$ \\
\hline $1-6$ & 931 & 39.28 & 7.74 & 599 & 39.85 & 8.26 \\
\hline $7-12$ & 1,003 & 40.97 & 7.52 & 1,127 & 41.23 & 8.23 \\
\hline $13-18$ & 638 & 41.76 & 7.79 & 867 & 42.00 & 7.70 \\
\hline $19-24$ & 506 & 43.23 & 7.84 & 828 & 42.36 & 7.65 \\
\hline $25-30$ & 375 & 42.89 & 7.86 & 621 & 42.12 & 7.51 \\
\hline $31-36$ & 442 & 43.82 & 8.29 & 742 & 42.92 & 8.07 \\
\hline $37-42$ & 308 & 44.75 & 7.38 & 565 & 42.65 & 8.55 \\
\hline $43-48$ & 360 & 43.79 & 7.38 & 572 & 43.64 & 7.53 \\
\hline $49-54$ & 231 & 44.38 & 7.12 & 361 & 43.52 & 8.01 \\
\hline $55-60$ & 307 & 44.45 & 7.75 & 471 & 44.12 & 8.15 \\
\hline $61-72$ & 440 & 45.11 & 7.76 & 668 & 44.29 & 7.93 \\
\hline $73-84$ & 341 & 44.57 & 7.58 & 589 & 44.16 & 8.24 \\
\hline $85-96$ & 293 & 45.90 & 7.69 & 506 & 44.30 & 7.98 \\
\hline $97-108$ & 214 & 44.66 & 7.62 & 347 & 44.82 & 7.56 \\
\hline $109-120$ & 217 & 45.10 & 7.20 & 410 & 44.54 & 8.08 \\
\hline
\end{tabular}

in the sample of consistent jobs, as measured by complexity. All trends show increasing functions across experience. General cognitive ability remained the strongest predictor across all levels of experience. Psychomotor ability was the second-best predictor across experience, the exception being the last two experience groups where perceptual speed became the secondbest predictor.

An examination of the correlations in Tables 4 and 5 suggested that the trends in ability-performance correlations may have been adversely influenced by the group involving 109-120 months of experience. Correlations defined in this group are more likely than those in most other groups to be adversely affected by sampling error due to the small sample size. Therefore, an additional analysis was conducted excluding the group having 109-120 months of experience. The resulting plots are shown in Figure 9. As can be seen, removal of the outlier had a definite impact on the trends. General cognitive ability now produces an inverse $U$ function, with values decreasing in the later experience groups. Perceptual speed and psychomotor ability show positively accelerating functions. In contrast to the first analysis, general cognitive ability is only the strongest predictor for groups having between 1 and 84 months of experience, after which psychomotor ability becomes the strongest predictor. When experience reaches 85-96 months, perceptual speed surpasses general cognitive ability to become the second strongest predictor. Psychomotor remains a stronger predictor of performance than perceptual speed across all levels of experience.

Trends in ability-performance correlations for consistent jobs, as measured by tolerance for repetition, are displayed in Figure 10 . The plot for the general cognitive ability-performance correlations shows a steady decrease across experience. 


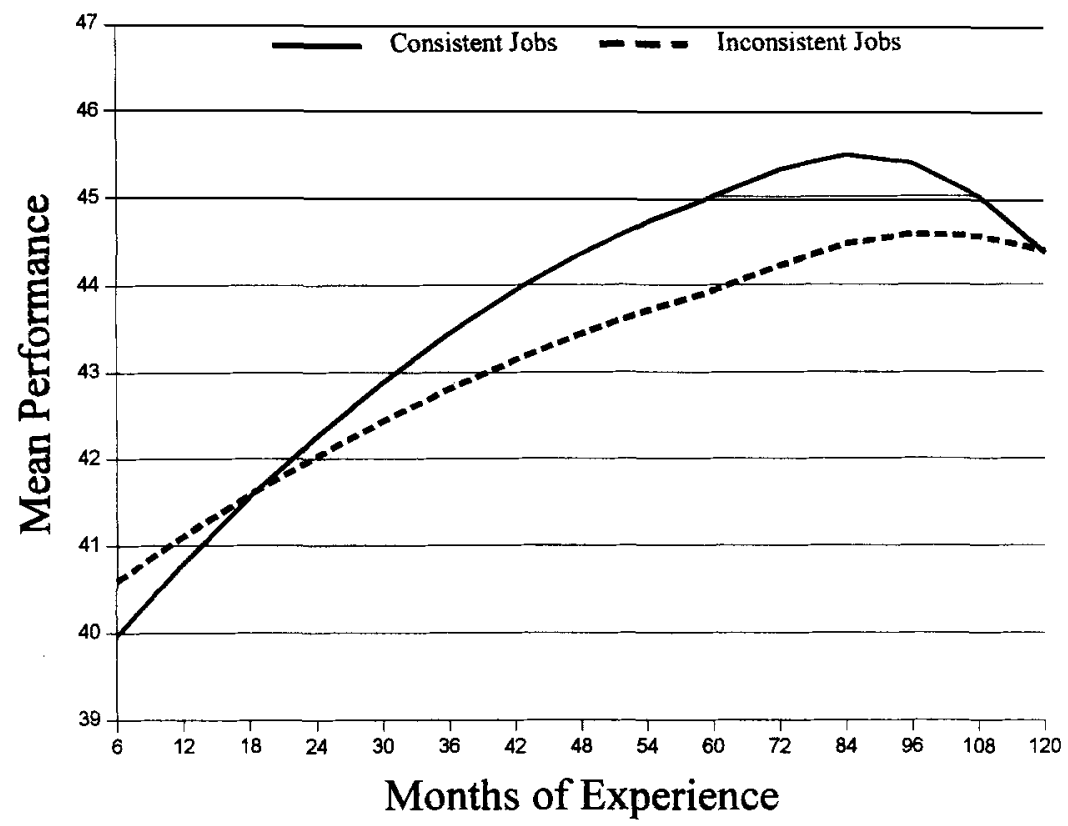

Figure 5. Trends in mean performance ratings for both consistent and inconsistent jobs, with tolerance for repetition as the measure of consistency. The least squares equations for each of the curves are as follows: consistent jobs, $R_{x y}=.93$ (experience) -.03 (experience) $)^{2}+39.06$; inconsistent jobs, $R_{x y}=.56$ (experience) .02 (experience) $^{2}+40.05$.

In contrast, the trends involving psychomotor ability show a continuously increasing function. The correlations involving perceptual speed show an inverșe $U$ function. General cognitive ability is the strongest predictor until $85-96$ months of experi- ence where psychomotor becomes the strongest predictor. Perceptual speed is initially the second strongest predictor until it is overtaken by psychomotor around 61-72 months of experience.

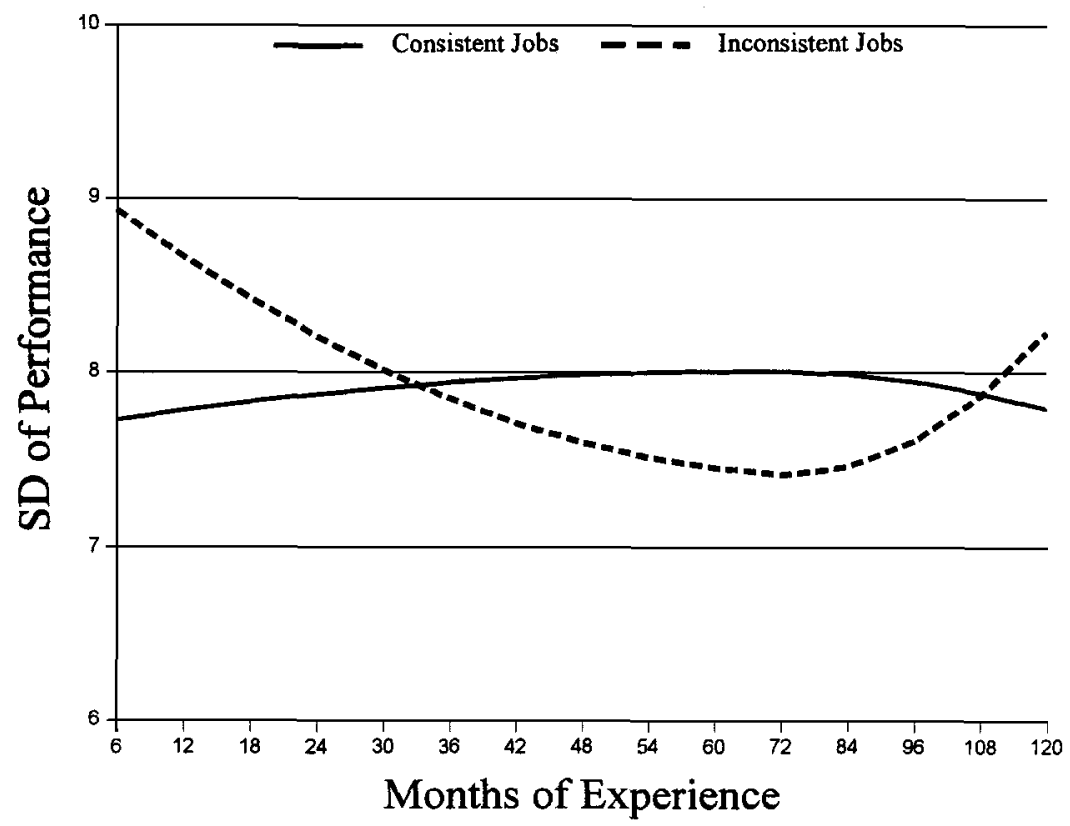

Figure 6. Trends in standard deviation of performance ratings for both consistent and inconsistent jobs, with complexity as the measure of consistency. The least squares equations for each of the curves are as follows: consistent jobs, $R_{x y}=.06$ (experience) -.003 (experience) ${ }^{2}+7.67$; inconsistent jobs, $R_{x y}=-.31$ (experience) +.01 (experience) $)^{2}+9.23$. 


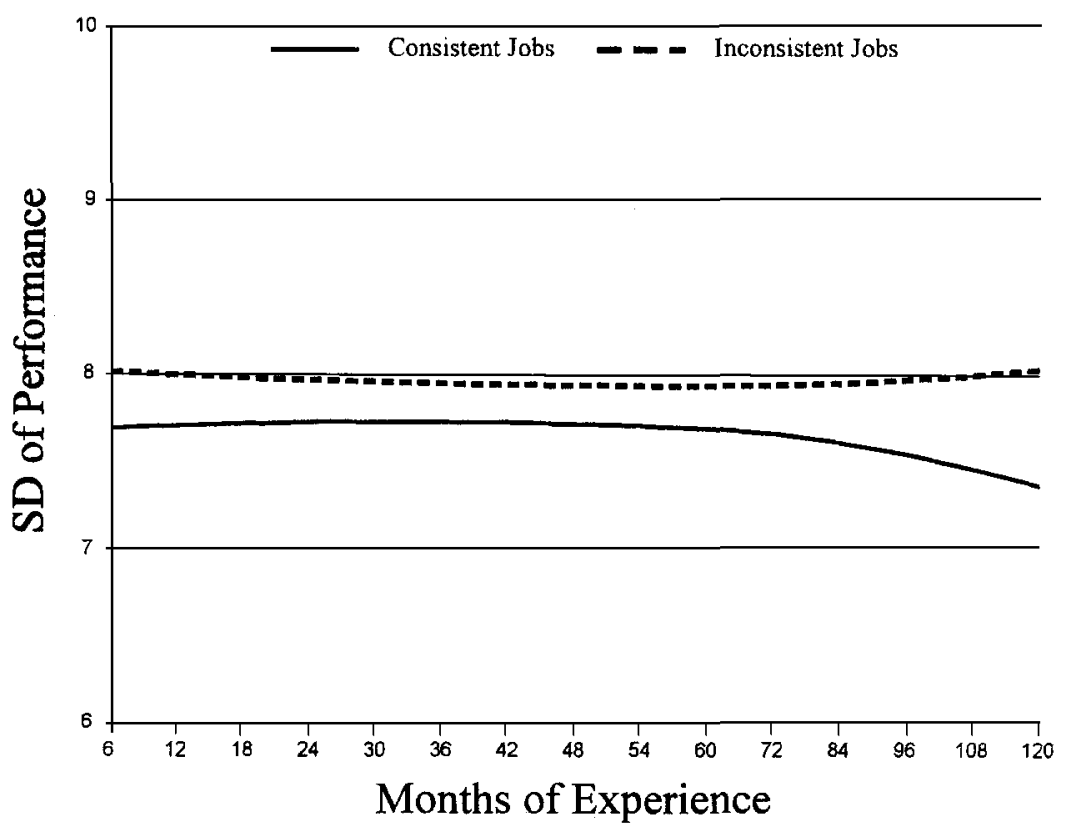

Figure 7. Trends in standard deviation of performance ratings for both consistent and inconsistent jobs, with tolerance for repetition as the measure of consistency. The least squares equations for each of the curves are as follows: consistent jobs, $R_{x y}=.02$ (experience) -.002 (experience) ${ }^{2}+7.67$; inconsistent jobs, $R_{x y}=-.02$ (experience) +.001 (experience) $^{2}+8.03$.

In sum, these results demonstrate that for consistent jobs the ability measure that best predicts performance changes across experience.

Inconsistent jobs. Figure 11 . shows the regression lines that best fit the sample of ability-performance correlations in the inconsistent sample, as measured by complexity. The plot involving general cognitive ability shows a linear increase across experience. The plots involving perceptual speed and psychomotor ability show $U$ functions. With the exception of the first two experience groups, general cognitive ability remained the strongest predictor across all levels of experience. The predictive power of perceptual speed, in relation to psychomotor ability, tended to vary across experience.

For the sample of inconsistent jobs, as measured by tolerance for repetition, plots for the regression lines that best fit the data are displayed in Figure 12. Both general cognitive ability and percep-

Table 4

Correlations Between Ability Composites and Supervisor Ratings for Consistent Jobs,

With Complexity as the Measure of Consistency

\begin{tabular}{|c|c|c|c|c|c|c|c|}
\hline \multirow{2}{*}{$\begin{array}{l}\text { Experience } \\
\text { (months) }\end{array}$} & \multirow[b]{2}{*}{$n$} & \multicolumn{2}{|c|}{ General cognitive } & \multicolumn{2}{|c|}{ Perceptual speed } & \multicolumn{2}{|c|}{ Psychomotor } \\
\hline & & Raw & Corrected & Raw & Corrected & Raw & Corrected \\
\hline $1-6$ & 905 & $.16 * *$ & .22 & $.15^{*}$ & .20 & $.17 *$ & .22 \\
\hline $7-12$ & 904 & $.17 * *$ & .23 & $.07 *$ & .09 & .04 & .05 \\
\hline $13-18$ & 594 & $.24^{* *}$ & .33 & .08 & .11 & $.09^{*}$ & .12 \\
\hline $19-24$ & 534 & $.16^{* *}$ & .22 & .06 & .08 & $.11^{* *}$ & .14 \\
\hline $25-30$ & 393 & $.24 * *$ & .33 & .07 & .09 & .07 & .09 \\
\hline $31-36$ & 455 & $.24 * *$ & .33 & $.14^{* *}$ & .19 & $.11 *$ & .14 \\
\hline $37-42$ & 313 & $.18^{* *}$ & .25 & .09 & .12 & $.15^{* *}$ & .20 \\
\hline $43-48$ & 319 & $.18^{* *}$ & .25 & .08 & .11 & .05 & .07 \\
\hline $49-54$ & 220 & $.20^{* *}$ & .28 & .11 & .15 & $.14 *$ & .18 \\
\hline $55-60$ & 293 & $.14 *$ & .19 & .11 & .15 & $.19 * *$ & .25 \\
\hline $61-72$ & 442 & $.27 * *$ & .37 & .09 & .12 & $.15^{* *}$ & .20 \\
\hline $73-84$ & 367 & .07 & .10 & $.19 * *$ & .26 & $.17^{* *}$ & .22 \\
\hline $85-96$ & 300 & $.13^{*}$ & .18 & $.12 *$ & .16 & $.18^{* *}$ & .23 \\
\hline $97-108$ & 203 & $.20 * *$ & .28 & .11 & .15 & $.19 * *$ & .25 \\
\hline $109-120$ & 207 & $.34 * *$ & .47 & $.22 * *$ & .30 & .10 & .13 \\
\hline
\end{tabular}

$* p=.05$. ** $p=.01$. 
Table 5

Correlations Between Ability Composites and Supervisor Ratings for Inconsistent Jobs, With Complexity as the Measure of Consistency

\begin{tabular}{|c|c|c|c|c|c|c|c|}
\hline \multirow{2}{*}{$\begin{array}{c}\text { Experience } \\
\text { (months) }\end{array}$} & \multirow[b]{2}{*}{$n$} & \multicolumn{2}{|c|}{ General cognitive } & \multicolumn{2}{|c|}{ Perceptual speed } & \multicolumn{2}{|c|}{ Psychomotor } \\
\hline & & Raw & Corrected & Raw & Corrected & Raw & Corrected \\
\hline $1-6$ & 34 & $.40^{*}$ & .54 & $.42 * *$ & .58 & .08 & .10 \\
\hline $7-12$ & 320 & $.16^{* *}$ & .22 & $.19 * *$ & .26 & $.18^{*}$ & .23 \\
\hline $13-18$ & 167 & $.29 * *$ & .39 & .13 & .18 & .07 & .09 \\
\hline $19-24$ & 173 & $.20^{* *}$ & .27 & $.20 * *$ & .28 & $.21 * *$ & .27 \\
\hline $25-30$ & 169 & $.22 * *$ & .30 & .10 & .14 & .09 & .12 \\
\hline $31-36$ & 193 & $.24 * *$ & .33 & .08 & .11 & .11 & .14 \\
\hline $37-42$ & 147 & $.33 * *$ & .45 & .07 & .10 & $.19 *$ & .25 \\
\hline $43-48$ & 180 & $.34 * *$ & .46 & .08 & .11 & .00 & .00 \\
\hline $49-54$ & 116 & .14 & .19 & -.11 & -.15 & .06 & .08 \\
\hline $55-60$ & 136 & $.22 * *$ & .30 & .10 & .14 & -.03 & -.04 \\
\hline $61-72$ & 235 & $.25 * *$ & .34 & -.02 & -.03 & .10 & .13 \\
\hline $73-84$ & 196 & $.22 * *$ & .30 & .05 & .07 & $.22 * *$ & .28 \\
\hline $85-96$ & 186 & $.21^{* *}$ & .29 & .12 & .17 & $.17^{*}$ & .22 \\
\hline $97-108$ & 142 & $.35^{* *}$ & .47 & $.23^{* *}$ & .32 & .05 & .07 \\
\hline $109-120$ & 161 & $.26 * *$ & .35 & $.19 *$ & .26 & .11 & .14 \\
\hline
\end{tabular}

${ }^{*} p=.05 . \quad{ }^{* *} p=.01$.

tual speed produced $U$ functions, whereas psychomotor produced an increasing linear function. General cognitive ability remained the strongest predictor across all levels of experience. Psychomotor ability was the second strongest predictor, for the most part, the exception being the initial and final levels of experience.

In sum, the sample of inconsistent jobs showed that general cognitive ability is consistently the strongest predictor of performance ratings, with its predictive ability increasing across time. The relative predictive ability of perceptual speed and psychomotor ability tended to vary across experience.

Comparing trends for consistent and inconsistent jobs. A comparison of graphs, produced by the regression lines that best fit the trends in ability performance correlations, showed that dividing jobs according to consistency produced differences in trends. These differences in trends emerged when consistency was measured by complexity. (see Figure 9 vs. Figure 10) as well as when consistency was measured by tolerance for repetition (see Figure 11 vs. Figure 12). An examination of the predictive strength of general cognitive ability shows that in the consistent sample the predictive strength tends to decrease with experience. For the inconsistent sample, in contrast, the tendency is for general cognitive ability to increase in predictive strength across experience.

A comparison of the relative position of curves, par-

Table 6

Correlations Between Ability Composites and Supervisor Ratings for Consistent Jobs, With Tolerance for Repetition as the Measure of Consistency

\begin{tabular}{|c|c|c|c|c|c|c|c|}
\hline \multirow{2}{*}{$\begin{array}{c}\text { Experience } \\
\text { (months) }\end{array}$} & \multirow[b]{2}{*}{$n$} & \multicolumn{2}{|c|}{ General cognitive } & \multicolumn{2}{|c|}{ Perceptual speed } & \multicolumn{2}{|c|}{ Psychomotor } \\
\hline & & Raw & Corrected & Raw & Corrected & Raw & Corrected \\
\hline $1-6$ & 931 & $.20^{* *}$ & .28 & .05 & .07 & $.07^{*}$ & .09 \\
\hline $7-12$ & 1,003 & $.17 * *$ & .23 & $.11 * *$ & .15 & .05 & .07 \\
\hline $13-18$ & 638 & $.33 * *$ & .45 & $.08 *$ & .11 & .05 & .07 \\
\hline $19-24$ & 506 & $.27 * *$ & .37 & .07 & .09 & $.14^{* *}$ & .18 \\
\hline $25-30$ & 375 & $.18 * *$ & .25 & $.14 * *$ & .19 & $.13^{* *}$ & .17 \\
\hline $31-36$ & 442 & $19 * *$ & .26 & .09 & .12 & .04 & .05 \\
\hline $37-42$ & 308 & $.28 * *$ & .38 & .10 & .13 & .03 & .04 \\
\hline $43-48$ & 360 & $.25 * *$ & .34 & $.15 * *$ & .20 & .09 & .12 \\
\hline $49-54$ & 231 & .08 & .11 & $.13^{*}$ & .18 & $.16^{*}$ & .21 \\
\hline $55-60$ & 307 & $.12 *$ & .17 & $.19 * *$ & .26 & $.12^{*}$ & .16 \\
\hline $61-72$ & 440 & $.23^{* *}$ & .32 & $10^{*}$ & .15 & $13^{* *}$ & .17 \\
\hline $73-84$ & 341 & $.15^{* *}$ & .21 & $.16^{* *}$ & .22 & $.19 * *$ & .25 \\
\hline $85-96$ & 293 & .10 & .14 & $.11^{*}$ & .15 & $.18^{* *}$ & .23 \\
\hline $97-108$ & 214 & $.15^{*}$ & .21 & .13 & .18 & $20^{* *}$ & .26 \\
\hline $109-120$ & 217 & $.26 * *$ & .36 & .10 & .14 & $.14^{*}$ & .18 \\
\hline
\end{tabular}

${ }^{*} p=.05 . \quad{ }^{* *} p=.01$. 
Table 7

Correlations Between Ability Composites and Supervisor Ratings for Inconsistent Jobs, With Tolerance for Repetition as the Measure of Consistency

\begin{tabular}{|c|c|c|c|c|c|c|c|}
\hline \multirow{2}{*}{$\begin{array}{l}\text { Experience } \\
\text { (months) }\end{array}$} & \multirow[b]{2}{*}{$n$} & \multicolumn{2}{|c|}{ General cognitive } & \multicolumn{2}{|c|}{ Perceptual speed } & \multicolumn{2}{|c|}{ Psychomotor } \\
\hline & & Raw & Corrected & Raw & Corrected & Raw & Corrected \\
\hline $1-6$ & 599 & $.26^{* *}$ & .36 & $.13^{* *}$ & .18 & .03 & .04 \\
\hline $7-12$ & 1,127 & $.30 * *$ & .41 & .05 & .07 & $.11^{* *}$ & .14 \\
\hline $13-18$ & 867 & $.22 * *$ & .30 & $.08 * *$ & .11 & $.12 * *$ & .16 \\
\hline $19-24$ & 828 & $.22 * *$ & .30 & $.08^{*}$ & .11 & $.10^{* *}$ & .13 \\
\hline $25-30$ & 621 & $.26^{* *}$ & .35 & .03 & .04 & .00 & .00 \\
\hline $31-36$ & 742 & $.27 * *$ & .37 & .03 & .04 & $.11 * *$ & .14 \\
\hline $37-42$ & 565 & $.22^{* *}$ & .30 & -.03 & -.04 & .04 & .05 \\
\hline $43-48$ & 572 & $.22 * *$ & .30 & -.07 & -.10 & -.01 & -.01 \\
\hline $49-54$ & 361 & $.21 * *$ & .29 & .02 & .03 & $-.12 *$ & .16 \\
\hline $55-60$ & 471 & $.29 * *$ & .39 & $.10^{*}$ & .14 & .09 & .12 \\
\hline $61-72$ & 668 & $.26 * *$ & .35 & .05 & .07 & $.12 * *$ & .16 \\
\hline $73-84$ & 589 & $.19^{* *}$ & .26 & $.12^{* *}$ & .17 & $.18 * *$ & .23 \\
\hline $85-96$ & 506 & $.25 * *$ & .34 & $.14 * *$ & .19 & $.14 * *$ & .18 \\
\hline $97-108$ & 347 & $.33^{* *}$ & .45 & .05 & .07 & $.12^{*}$ & .16 \\
\hline $109-120$ & 410 & $.28 * *$ & .38 & $.16^{* *}$ & .22 & .09 & .12 \\
\hline
\end{tabular}

$* p=.05 . \quad * * p=.01$.

ticular those involving general cognitive ability and psychomotor ability, showed that dividing the sample of jobs by consistency influenced which ability would predict best across experience. In the consistent sample, general cognitive ability was the strongest predictor initially but was later overtaken by psychomotor ability and perceptual speed. In contrast, the inconsistent sample produced plots that showed general cognitive to be the strongest predictor across all levels of experience.

\section{Discussion}

Previous research has examined the ability of Ackerman's (1988) model to predict the relationship between abilities and

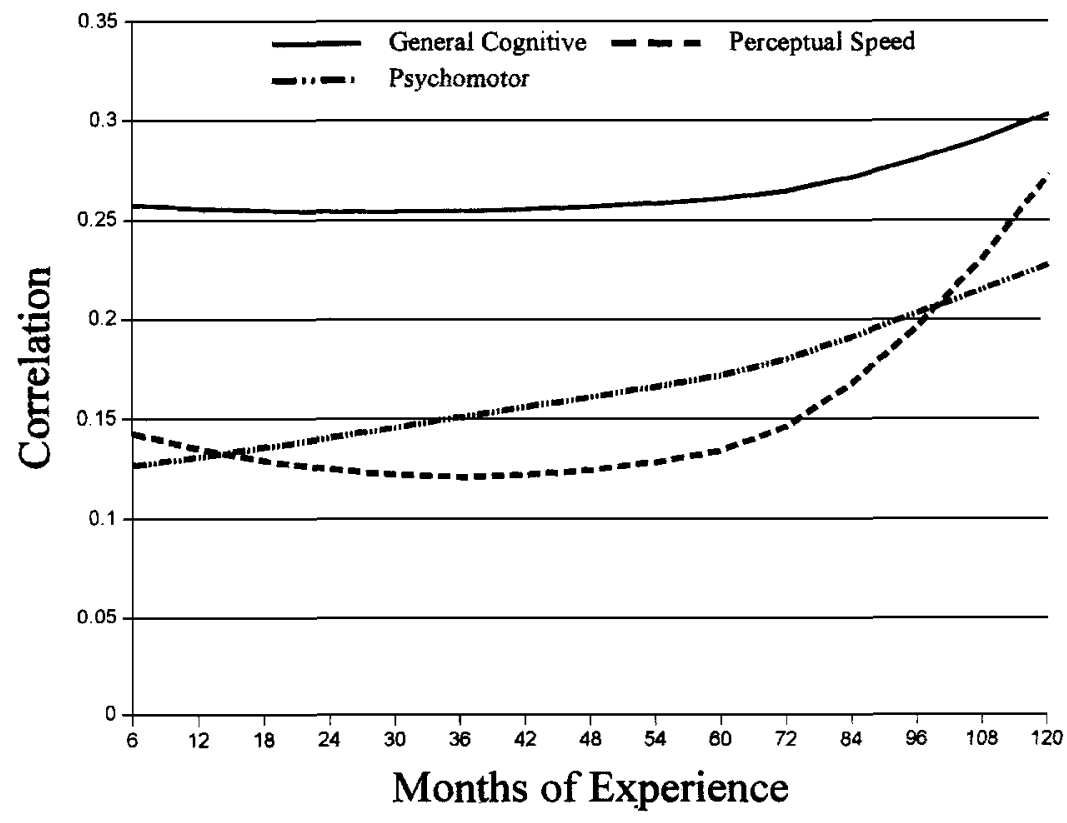

Figure 8. Trends in ability-performance correlations for consistent jobs, with complexity as the measure of consistency. The least squares equations for each of the curves are as follows: general cognitive, $R_{x y}=-.002$ (experience) +.0002 (experience) $)^{2}+.26 ;$ perceptual speed, $R_{x y}=-.01$ (experience) +.001 (experience) $)^{2}+$ .15 ; psychomotor, $R_{x y}=.004$ (experience) +.0001 (experience) ${ }^{2}+.12$. 


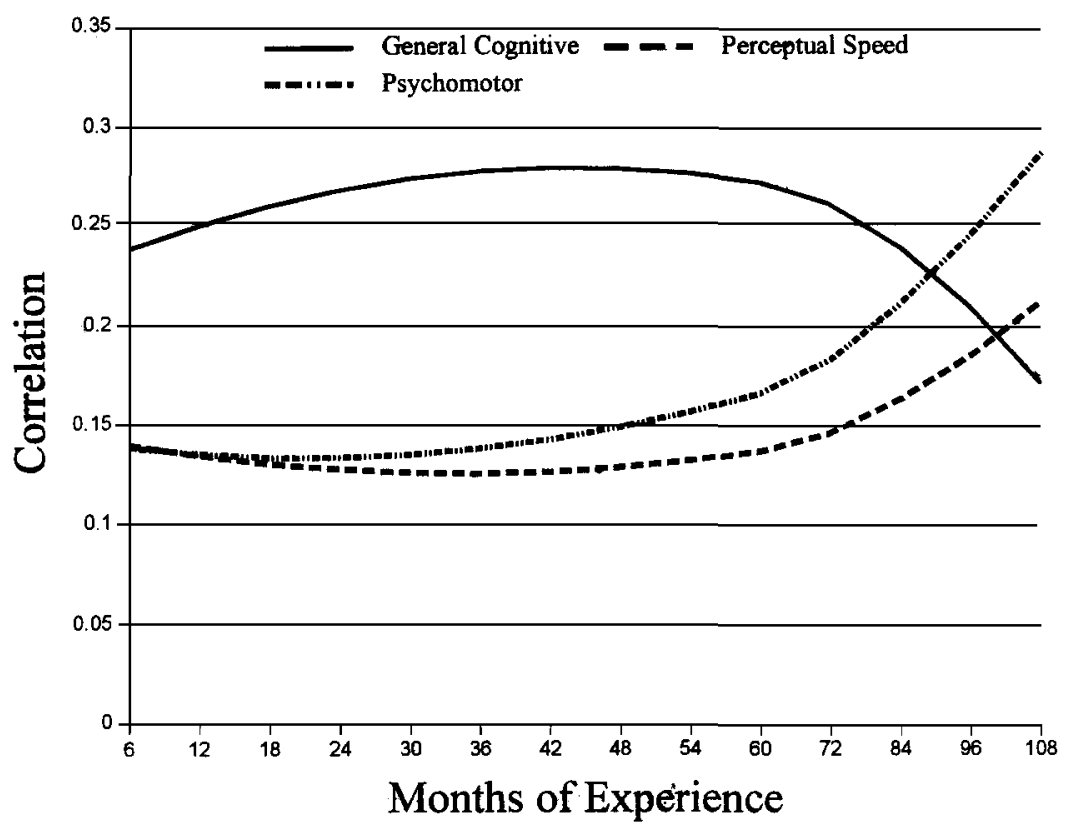

Figure 9. Trends in ability-performance correlations for consistent jobs, with complexity as the measure of consistency, extreme values removed. The least squares equations for each of the curves are as follows: general cognitive, $R_{x y}=.02$ (experience) +.001 (experience) ${ }^{2}+.22$; perceptual speed, $R_{x y}=-.01$ (experience) +.001 (experience) $)^{2}+.15$; psychomotor, $R_{x y}=-.01$ (experience) +.001 (experience) ${ }^{2}+.14$.

performance within laboratory settings. The current research tested several of the major tenets of Ackerman's theory within an applied setting using the GATB database. Results demonstrated that learning curves and trends in validity coefficients differ with experience when the sample was divided according to job consistency, as predicted by Ackerman's model.

The following section will discuss the major findings of the current research. First, results will be discussed as they apply to

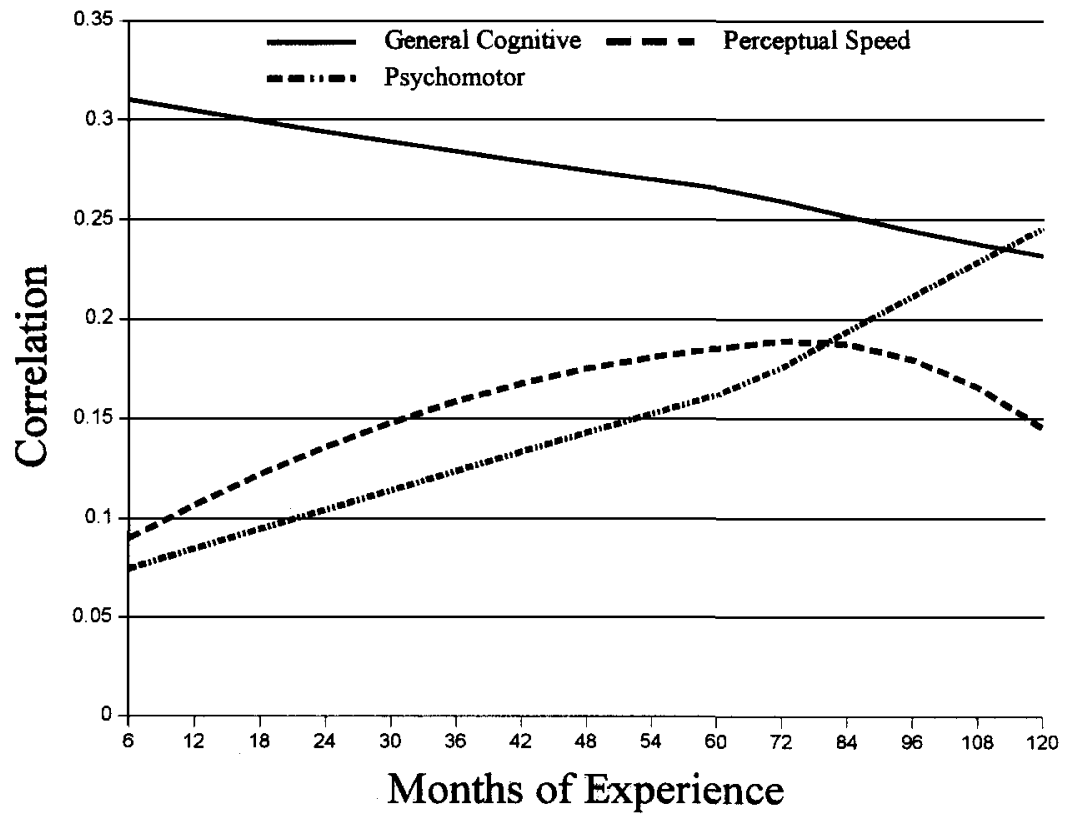

Figure 10. Trends in ability-performance correlations for inconsistent jobs, with complexity as the measure of consistency. The least squares equations for each of the curves are as follows: general cognitive, $R_{x y}=-.01$ (experience) +.0001 (experience) $)^{2}+.32$; perceptual speed, $R_{x y}=.02$ (experience) -.001 (experience) $)^{2}+.07$; psychomotor, $R_{x y}=.01$ (experience) -.0001 (experience) $)^{2}+.07$. 
FARRELL AND MCDANIEL

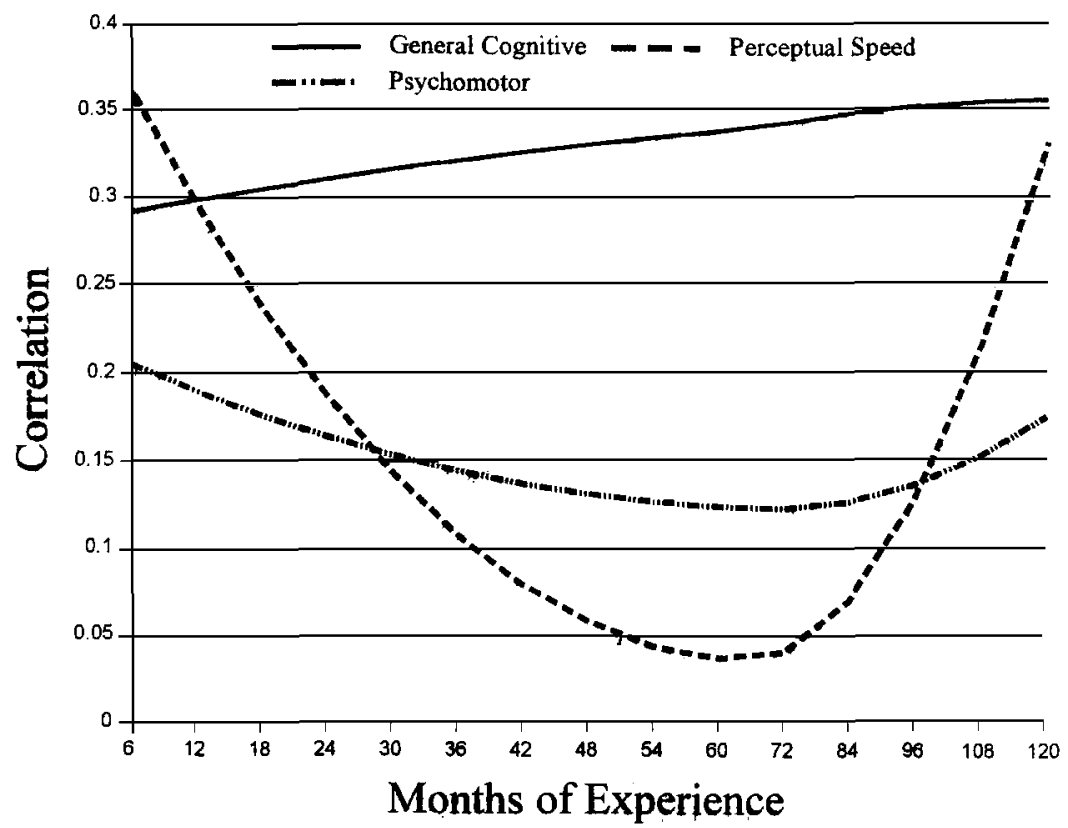

Figure 11. Trends in ability-performance correlations for consistent jobs, with tolerance for repetition as the measure of consistency. The least squares equations for each of the curves are as follows: general cognitive, $R_{x y}$ $=.01$ (experience) -.0002 (experience) ${ }^{2}+.29$; perceptual speed, $R_{x y}=-.08$ (experience) +.004 (experience $)^{2}+.43 ;$ psychomotor, $R_{x y}=-.02$ (experience) +.001 (experience) $)^{2}+.22$.

each hypothesis with attention being paid to how current findings relate to previous research. Next, implications for theoretical development will be addressed. Finally, limitations of the current study, as well as future directions for applied research, will be discussed.

\section{Discussion of Hypotheses}

Although the nature of the GATB data did not allow a definitive test of Ackerman's (1988) model, tests were conducted for the following: differences in the shape of learn-

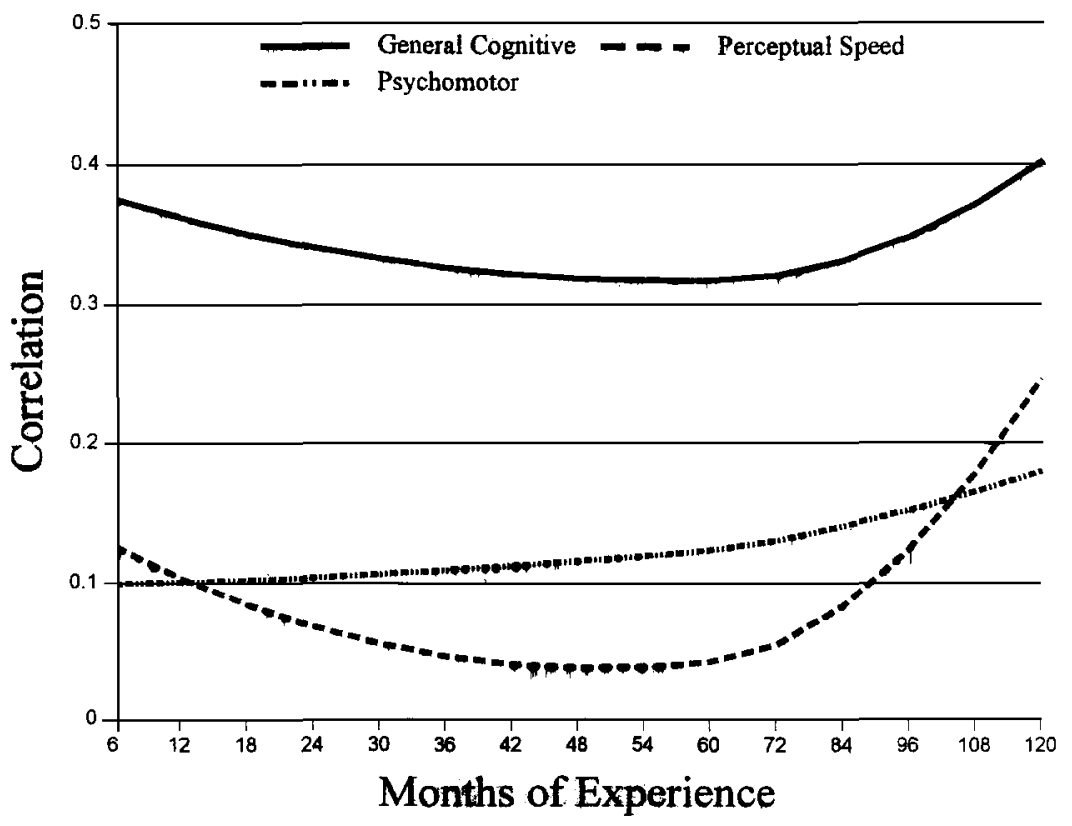

Figure 12. Trends in ability-performance cotrelations for inconsistent jobs, with tolerance for repetition as the measure of consistency. The least squares equations for each of the curves are as follows: general cognitive, $R_{x y}$ $=-.02$ (experience) +.001 (experience) $)^{2}+.39$; perceptual speed, $R_{x y}=-.03$ (experience) +.002 (experience) $^{2}+.15 ;$ psychomotor; $R_{x y}=.001$ (experience) +.002 (experience) ${ }^{2}+.10$. 
ing curves when jobs are divided according to job consistency, differences in the relationship between variability in performance and experience for consistent and inconsistent jobs, and differences in trends in ability-performance correlations across experience for consistent and inconsistent jobs. The results of each of these hypotheses will be discussed in turn.

Learning curves. Previous applied research has demonstrated that learning curves for jobs are monotonically increasing and negatively accelerated (Blankenship \& Taylor, 1938; Ghiselli \& Brown, 1947; Taylor \& Smith, 1956). However, the shapes of these curves occurred over a period of months. The results of the current research have shown that learning curves can occur over a 10-year period. This extended period of learning corroborated previous theory and research in expertise (e.g., Simon \& Chase, 1973) and the industrial/organizational psychology literature (e.g., McDaniel, 1986; McDaniel et al., 1988; Schmidt et al., 1988). It would appear that learning in organizations occurs beyond initial training with continued learning on-the-job over a period of years.

The finding that both consistent and inconsistent jobs show monotonically increasing and negatively accelerated curves does contrast with the work of Avolio et al. (1990), which found that low complexity clerical jobs show an inverse $U$-shaped curve. This difference might be due to Avolio et al.'s (1990) use of Gottfredson's (1986) occupational taxonomy to classify jobs into five categories, as opposed to the current research that used an extreme groups design with the complexity measure and two groups with the tolerance for repetition measure to assign jobs to consistency groups. It is possible that the occupational taxonomy and consistency measures are assessing different constructs.

A comparison of learning curves demonstrated that due to the difference in cognitive demands shapes of learning curves differ in a predictable fashion when the jobs are divided according to consistency. It would appear that the sustained reliance on general cognitive ability, in inconsistent jobs, results in longer periods of time to obtain proficiency.

Variability in performance. The current research examined changes in performance variability within an applied setting using the standard deviation of performance as the measure of variability, as recommended by Anastasi (1934). Support for the hypothesis was mixed. As predicted, variability in performance remained stable across time for consistent jobs. Contrary to predictions, performance variability for inconsistent jobs showed a relatively flat curve or an inverse $U$ function.

A number of explanations could account for the mixed findings. One potential problem with the sample involves the effects of selection and attrition, issues inherent in cross-sectional experimental designs. It is possible that in the inconsistent sample variability actually increased. However, due to attrition at the extreme ends of the distribution, due to occurrences such as promotions and firings, the actual trends in variability may have been obscured.

In addition to sample problems, the nature of the performance criteria (i.e., supervisor ratings) may have affected the results. Although the standard deviation of performance was used, as recommended by Anastasi (1934), the use of supervisor ratings may have produced results different from those involving attainment measures (Anastasi, 1934) or RT measures (Ackerman,
1987). Rating bias, then, could have produced the unexpected findings involving trends in performance variability.

Trends in ability-performance correlations. Building on previous research that assessed changes in ability-performance correlations within applied settings (e.g., Bass, 1962; Ghiselli, 1973), the present findings produced modest support for the assertions made by Ackerman (1988). When jobs were divided according to consistency, patterns emerged in the data that supported the trends in validity coefficients proposed by Ackerman's (1988) model, particularly those trends involving general cognitive and psychomotor ability. In this section, findings concerning trends in ability-performance correlations over experience will be discussed.

For the sample of consistent jobs, general cognitive ability was the strongest predictor initially but declined over the course of experience, giving way to psychomotor ability as the strongest predictor. This shift in relative predictive strength occurred due to the shift in cognitive abilities that underlies skill acquisition in consistent jobs. Initially, general cognitive and broad content abilities are important in skill acquisition in that they are important in learning rules of a job, the job elements, and routines. However, once the routines become automatic, there is less of a demand on higher cognitive resources. Consequently, psychomotor ability becomes important.

In contrast to jobs with primarily consistent tasks, jobs with primarily inconsistent components showed a different pattern of correlations across experience. General cognitive ability was consistently the strongest predictor of performance relative to perceptual speed and psychomotor ability. This occurred because the jobs in the inconsistent sample do not allow for automaticity, thereby they continually demand higher cognitive resources.

Although the findings involving the differences in trends in correlations for general cognitive ability and psychomotor ability were compelling, the comparison of trends for perceptual speed did not support the hypothesis that during the knowledge compilation phase of skill acquisition perceptual speed would be the most important ability underlying performance. It may be that the way in which the current study assessed perceptual speed was inadequate (e.g., paper and pencil). In Ackerman's (1988) work, perceptual speed was measured via computer.

\section{Implications for Theory}

Although results were mixed, findings regarding the nature of learning within an applied setting suggest several implications for theory in the areas of learning, expertise, and skill acquisition. The relation between the current study's findings and each of these theoretical areas is presented in this section.

Learning in organizations. Previous applied research has demonstrated that learning can occur on the job for a number of months (e.g., Ghiselli \& Brown, 1947) and even years (e.g., McDaniel, 1986; McDaniel et al., 1988; Schmidt et al., 1988). The present study corroborates these findings by showing that learning can occur for a period of 10 years, a finding that supports theory and research in expertise (Ericsson, Krampe, \& Tesch-Romer, 1993; Simon \& Chase, 1973). These findings suggest that learning extends far beyond initial socialization and training and well into the career of the individual. 
If skill acquisition on a job can extend over a period of years, and perhaps throughout the career of the worker, it behooves organizations to view their employees as having the capability to continuously learn. Such a perspective would suggest that, in addition to recognizing the impact of abilities on job performance, a focus on work as being extended deliberate practice may prove beneficial in improving performance levels over time. Consequently, variables such as motivation and personality become increasingly important in ensuring extended effort on the part of the employee (cf. Ericsson et al., 1993). The role of the manager, then, could be seen as a coach who monitors performance, provides developmental feedback, and maintains the employees' motivation to learn.

Although the current research did not examine the impact that new technology could have on learning, it is possible that rapidly changing technology could influence learning curves across an individual's career. As noted by Murphy (1989), during periods of technological change, increased demands are placed on the employees to learn novel information. During such periods, demands on employees' mental abilities, as well as perception of their ability to learn (cf. Dweck, 1986), are likely to influence the extent to which they adapt to the new technology. During such transitional phases, optimal learning could be achieved if managers and trainers clarify instructional objectives and increase attempts to maintain employees' motivation.

Ackerman's model. Although the current study did not provide a definitive test of Ackerman's (1988) model, it did show that important constructs in the model could be defined and assessed within a field setting. Based upon the current studies findings, several conclusions can be drawn regarding the relative accuracy and utility of Ackerman's model of skill acquisition, as opposed to other models that attempt to explain changes in ability performance correlations over time (e.g., Hulin et al., 1990).

The theoretical work of Hulin and colleagues (e.g., Hulin et al., 1990) has argued that, due to the use of specific abilities in a job, ability scores will increase across the course of skill acquisition. However, the current study demonstrated that abilities tend to decrease across experience (see Table 1). It is possible that motivational effects, as well as selection (i.e., promotion of higher scoring individuals), might have produced the current results. However, due to the nature of the data, it was not possible to test for the effects of motivation or selection.

Hulin and colleagues also asserted that the relationship between ability and performance will decrease across time (cf. Hulin et al., 1990) due to the impact of increases in ability levels. A visual inspection of the ability-performance correlation trends shows that the opposite is more likely: Trends in ability-performance correlations actually appear to increase over experience.

\section{Limitations}

An examination of the current research reveals a number of limitations regarding the experimental design, measures, and theoretical perspective. To begin, the current study was conducted in a field setting using a cross-sectional design. As noted by Schaie (1977), a serious problem with cross-sectional designs is that one must assume that the cohorts are equivalent, a position Schaie regarded as untenable. Furthermore, statistical control of cohort differences is difficult and should involve a theoretical basis (Schaie, 1977). The fact that correlations between all three of the ability composites and experience were negative (see Table 1) suggests that cohorts were not equivalent, with later groups having lower levels of the abilities than earlier groups.

The way in which the current study defined experience and constructed experience cohorts may have also impacted the results. The only available measure of experience on a task was an estimation, by employees, of how long they had been in a particular profession. It is likely that skills used in another profession may also be used in the current job. In regard to the construction of experience cohort, we collapsed several jobs across several organizations to achieve reasonable sample sizes across groups. Although jobs were classified according to consistency, it is unclear if dissimilarities in jobs may have added error variance. Although an examination of a few select jobs across experience might have controlled this problem, the restriction of the sample to a few jobs would not have produced large enough cohorts for the current analyses.

A second limitation of the current research involves the use of supervisor ratings as the measure of performance. Ackerman's laboratory work (e.g., Kanfer \& Ackerman, 1989) involved quantifiable measures of performance that could be assessed automatically by computer (i.e., landings on the TRACON task), thereby minimizing the impact that perceptual bias could have on performance measures. The use of supervisor ratings in the current study allowed for the possibility of rater bias in performance ratings. For example, because experience is highly correlated with age, raters may have partially based their ratings on the age of the individual and not on their actual performance.

The use of supervisor ratings as the performance measure may have been problematic from a methodological perspective. Because multiple supervisors were used, it is not likely that the data were recorded the same way across each job. Although the same performance appraisal rating form was used for all sample members, it is likely that the actual administration and recording of the supervisor ratings varied somewhat across raters.

In addition to the criteria (i.e., performance measure), some concerns need to be raised with respect to the predictors used in the current study (i.e., ability composites). Because of the high correlations between ability composites, the effects of general cognitive ability were partialled out of the correlations involving perceptual speed and psychomotor ability. Although this procedure succeeded in eliminating the relationship between general cognitive and the two residualized variables, it is unclear what impact this procedure may have had on test validity. For example, the weak results in relation to perceptual speed may be attributable to the fact that true variance was eliminated in the partial correlations.

The use of the psychomotor tests in the GATB also raised some concerns. None of the psychomotor measures in the current study used the RT methodology that was used in Ackerman's work. In addition, because there are likely to be a number of motor skills involved in the execution of skilled behavior in the current sample of jobs, the psychomotor ability measures used in the current study may not have been adequate. The current measures only assessed psychomotor behavior involving finger tapping and hand-eye coordination, so they were unable to assess other motor skills or integration of different motor skills.

A final consideration involves the theoretical model for the current research. As noted by Ackerman (1987), model underspecification can result in anomalous results. For example, the current research focused on the role of abilities in skill acquisition 
across experience. However, due to the length of time required to learn within an organization, it is likely that motivational and personality variables will affect the extent to which a person improves performance. However, the current research was unable to assess either motivational or personality variables.

\section{Future Directions}

The present research has highlighted several potential areas of focus for future theory and applied research. It is suggested that future research in skill acquisition might focus on methodological issues (e.g., experimental design) and the integration of theoretical models.

Future studies could benefit by using designs, other than the cross-sectional approach used in the current study, that could reduce some of the concerns raised by the current research. For example, attempts to examine skill acquisition across time could involve the use of longitudinal designs. Longitudinal designs are not without their own set of concerns, not the least of which is that they might outlive the investigator (Schaie \& Gribbon, 1975), therefore designs such as the cohort sequential might prove useful (Schaie \& Hertzog, 1982).

Another methodological issue concerns the use of ability and performance measures in skill acquisition research. In terms of ability measures, future applied research would benefit from the use of generally accepted measures of the various constructs as well as the use of multiple measures. The use of widely accepted research measures (e.g., Raven's Progressive Matrices) would allow for better comparison across various experiments. The use of multiple measures is sensible for a number of reasons. For example, there are likely to be a number of motor systems, so several psychomotor tests could be used. Furthermore, the use of multiple tests would allow the use of factor analytic techniques such as those used in Ackerman's work (cf. Ackerman, 1986).

The use of multiple measures of job performance would also be of benefit to future research. As noted previously, the reliance of the current study's findings on performance ratings raises issues concerning rater bias. The use of multiple performance measures would allow the use of more objective criteria such as attainment and RT measures, which could be assessed via computer. In addition to reducing rater bias, the use of attainment criteria would have the advantage of providing a metric through which previous findings in performance variability could be compared.

A final consideration for future research concerns the integration of Ackerman's (1988) work with other theoretical work in expertise and social learning. For example, Ericsson et al. (1993) have proposed that because expertise is acquired over extended periods involving focused practice, motivation and personality variables will likely be of greater importance than more primary abilities (e.g., general cognitive). Because Ackerman's work is expanding to include personality and motivational variables (e.g., Ackerman, Kanfer, \& Goff, 1995), these constructs will likely provide points of comparison and integration of theory.

In addition to motivational and personality constructs, Ackerman's (1988) work and the expertise literature may serve as compliments in a broader view of learning. Ackerman's work provides a foundation of cognitive abilities that differentially impact performance across skill acquisition. Expertise research provides a view of higher cognitive processing (e.g., knowledge structure and strategy) that is likely to be acquired and influenced by more basic cognitive abilities. Future theory and research could focus on the investigation of the interrelationship between cognitive abilities, higher cognitive structures, personality, and motivational variables. Such investigations would enable comparisons between, for example, the role that primary abilities play in acquiring expertise and the role of personality and motivational variables (cf. Ericsson et al., 1993).

Social learning theory (cf. Bandura, 1986) is a second theoretical perspective that could be incorporated into a broader framework of skill acquisition. By taking into account situational influences that are social in nature (e.g., culture, mentoring), one can view the influences of more primary abilities within a larger context. Work in expertise has already suggested that competent coaching is necessary in acquiring proficiency (cf. Ericsson et al., 1993; Ericsson \& Smith, 1991). However, both Ackerman's work and the expertise literature have both focused on individual variables (i.e., cognitive processing) and could benefit by considering the role that social interaction plays in impacting the quality of instruction and individual motivation to continue learning on the job.

By providing a context that takes into account social influences, future theory can attempt to account for problems that may have impacted the current research. For example, because performance occurs within the social and political context of an organization, models incorporating social influences can define influences, such as personal attraction, that could result in rater bias. Furthermore, cultural influences, such as performance norms, might also have an impact if higher ability workers are encouraged to conform to lower performance standards. In short, the consideration of these social influences could add explanatory power beyond the individual variables of abilities, motivation, and personality.

\section{References}

Ackerman, P. L. (1986). Individual differences in information processing: An investigation of intellectual abilities and task performance during practice. Intelligence, 10, 109-139.

Ackerman, P. L. (1987). Individual differences in skill learning: An integration of psychometric and information processing perspectives. Psychological Bulletin, 102, 3-27.

Ackerman, P. L. (1988). Determinants of individual differences during skill acquisition: Cognitive abilities and information processing. Journal of Experimental Psychology: General, 117, 288-313.

Ackerman, P. L. (1992). Predicting individual differences in complex skill acquisition: Dynamics of ability determinants. Journal of Applied Psychology, 77, 598-614.

Ackerman, P. L., \& Kanfer, R. (1993). Integrating laboratory and field study for improving selection: Development of a battery for predicting air traffic controller success. Journal Applied Psychology, 78, 413-432.

Ackerman, P. L., Kanfer, R., \& Goff, M. (1995). Cognitive and noncognitive determinants and consequences of complex skill acquisition. Journal of Experimental Psychology: Applied, 1, 270-304.

Anastasi, A. (1934). Practice and variability: A study in psychological method. Psychological Monographs, 45, (5, Whole No. 204).

Anderson, J. R. (1982). Acquisition of cognitive skill. Psychological Review, 89, 369-406.

Anderson, J. R. (1983). The architecture of cognition. Cambridge, MA: Harvard University Press.

Avolio, B. J., Waldman, D. A., \& McDaniel, M. A. (1990). Age and work performance in non-managerial jobs: The effects of experience and occupational type. Academy of Management Joumal, 33, 407-422.

Bandura, A. (1986). Social foundations of thought and action: A social cognitive theory. Englewood Cliffs, NJ: Prentice Hall. 
Barrett, G. V., Caldwell, M. S., \& Alexander, R. A. (1985). The concept of dynamic criteria: A critical reanalysis. Personnel Psychology, 38, 41-56.

Barrett, G. V., Caldwell, M. S., \& Alexander, R. A. (1989). The predictive stability of ability requirements for task performance: A critical analysis. Human Performance, 2, 167-181.

Bass, B. M. (1962). Further evidence on the dynamic character of criteria. Personnel Psychology, 15, 93-97.

Blankenship, A. B., \& Taylor, H. R. (1938). Prediction of vocational proficiency in three machine operations. Journal of Applied Psychology, 22, 518-526.

Bray, D. W., \& Howard, A. (1983). The AT\&T longitudinal studies of managers. In K. W. Schaie (Ed.), Longitudinal studies of adult psychological development (pp. 266-312). New York: Gilford Press.

Campion, M. A. (1989). Ability requirement implications of job design: An interdisciplinary perspective. Personnel Psychology, 42, 1-24.

Dweck, C. S. (1986). Motivational processes affecting leaming. American Psychologist, 41, 1040-1048.

Educational Testing Service. (1967). School and College Abilities Test, Series II. Princeton, NJ: Author.

Ericsson, K. A., Krampe, R. T., \& Tesch-Romer, C. (1993). The role of deliberate practice in the acquisition of expert performance. Psycholog. ical Review, 100, 363-406.

Ericsson, K. A., \& Smith, J. (Eds.). (1991). Toward a general theory of expertise: Prospects and limits. Cambridge, England: Cambridge University Press.

Fine, S. A. (1955). A structure of worker functions. Personnel and Guidance Journal, 34, 66-73.

Fitts, P., \& Posner, M. I. (1967). Human performance. Belmont, CA: Brooks/Cole.

Fleishman, E. A., \& Mumford, M. D. (1989a). Abilities as causes of individual differences in skill acquisition. Human Performance, 2, 201223.

Fleishman, E. A., \& Mumford, M. D. (1989b). Individual attributes and training performance. In I. L. Goldstein (Ed.), Training and career performance. San Francisco: Jossey-Bass.

Gandy, J. A. (1986, June). Job complexity, aggregated samples, and aptitude test validity: Meta-analysis of the General Aptitude Test Battery data base. Paper presented to the International Personnel Management Association, San Francisco, CA.

Ghiselli, E. E. (1966). The validity of occupational tests. New York: Wiley.

Ghiselli, E. E. (1973). The validity of aptitude tests in personnel selection. Personnel Psychology, 26, 461-477.

Ghiselli, E. E., \& Brown, C. W. (1947). Learning in accident reduction. Joumal of Applied Psychology, 31, 580-582.

Giniger, S., Dispenzieri, A., \& Eisenberg, J. (1983). Age, experience, and performance on speed and skill jobs in an applied setting. Journal of Applied Psychology, 68, 469-475.

Gottfredson, L. S. (1986). Occupational Aptitude Pattern Maps: Development and implications for a theory of job aptitude requirements. Journal of Vocational Behavior, 29, 254-291.

Gutenberg, R. L., Arvey, R. D., Osburn, H. G., \& Jeanneret, P. R. (1983). Moderating effects of decision-making/information-processing job dimensions on test validities. Journal of Applied Psychology, 68, 602608.

Hartigan, J. A., \& Wigdor, A. K. (1989). Fairness in employment testing: Validity generalization, minority issues, and the General Aptitude Test Battery. Washington, DC: National Academy Press.

Hasher, L., \& Zacks, R. T. (1979). Automatic and effortful processes in memory. Journal of Experimental Psychology: General, 108, 356-388.

Hasher, L., \& Zacks, R. T. (1984). Automatic processing of fundamental information: The case of frequency of occurrence. American Psychologist, 39, 1372-1388.

Henry, R. A., \& Hulin, C. L. (1987). Stability of skilled performance across time: Some generalizations and limitations on utilities. Journal of Applied Psychology, 72, 457-462.

Henry, R. A., \& Hulin, C. L. (1989). Changing validities: Ability-perfor- mance relations and utilities. Journal of Applied Psychology, 74, 365367.

Hulin, C. L., Henry, R. A., \& Noon, S. L. (1990). Adding a dimension: Time as a factor in the generalizability of predictive relationships. Psychological Bulletin. 107, 328-340.

Hunter, J. E. (1983a). Test validation for 12,000 jobs: An application of job classification and validity generalization analysis for the General Aptitude Test Battery (U.S. Employment Service Test Research Report No. 45). Washington, DC: U.S. Department of Labor.

Hunter, J. E. (1983b). The dimensionality of the General Aptitude Test Battery (GATB) and the dominance of general factors over specific factors in the prediction of job performance for the U.S. Employment Service (U.S. Employment Service Test Research Report No. 44). Washington, DC: U.S. Department of Labor.

Hunter, J. E., \& Hunter, R. F. (1984). Validity and utility of alternative predictors of job performance. Psychological Bulletin, 96, 72-98.

Hunter, J. E., Schmidt, F. L., \& Jackson, G. B. (1982). Meta-analysis: Cumulating research across studies. Beverly Hills, CA: Sage.

James, W. (1890). The principles of psychology (Vol. 1). New York: Holt.

Kanfer, R., \& Ackerman, P. L. (1989). Motivational and cognitive abilities: An integrative/aptitude-treatment interaction approach to skill acquisition [Monograph]. Journal of Applied Psychology, 74, 657-690.

Kaufman, H. G. (1972). Relations of ability and interest to currency of professional knowledge among engineers. Journal of Applied Psychology, 56, 495-499.

Kaufman, H. G. (1974). Relationship of early work challenge to job performance, professional contributions, and competence of engineers. Journal of Applied Psychology, 59, 377-379.

Kincaid, M. (1925). A study of individual differences in learning. Psychological Review, 32, 34-53.

King, L. M., Hunter, J. E., \& Schmidt, F. L. (1980). Halo in a multidimensional forced choice performance and evaluation scale. Journal of Applied Psychology, 65, 502-516.

Laberge, D., \& Samuels, S. J. (1974). Toward a theory of automatic information processing in reading. Cognitive Psychology, 6, 293-323.

McCormick, E. J., Jeanneret, P. R., \& Mecham, R. C. (1972). A study of job characteristics and job dimensions as based on the Position Analysis Questionnaire (PAQ). Journal of Applied Psychology, 56, 347-368.

McDaniel, M. A. (1986). The evaluation of a causal model of job performance: The inter-relationships of general mental ability, job experience, and job performance. Unpublished doctoral dissertation, The George Washington University.

McDaniel, M. A., Schmidt, F. L., \& Hunter, J. E. (1988). Job experience correlates of performance. Journal of Applied Psychology, 73, 327-330.

McEvoy, G. M., \& Cascio, W. F. (1989). Cumulative evidence of the relationship between age and job performance. Joumal of Applied Psychology, 74, 11-17.

McNemar, Q. (1962). Psychological statistics. New York: John Wiley \& Sons.

Murphy, K. R. (1989). Is the relationship between cognitive ability and job performance stable over time? Human Performance, 2, 183-200.

Pearlman, K., Schmidt, F. L., \& Hunter, J. E. (1980). 'Validity generalization results for tests used to predict training success and job proficiency in clerical occupations. Journal of Applied Psychology, 65, 373-406.

Posner, M. I., \& Snyder, C. R. R. (1974). Attention and cognitive control. In R. L. Solso (Ed.), Information processing and cognition: The Loyola symposium. Hillsdale, NJ: Erlbaum.

Rothstein, H. R. (1990). Inter-rater reliability of job performance ratings: Growth to asymptote level with increasing opportunity to observe. Journal of Applied Psychology, 75, 322-327.

Schaie, K. W. (1977). Quasi-experimental designs in the psychology of aging. In J. E. Birren \& K. W. Schaie (Eds.), Handbook of psychology and aging. New York: Van Nostrand.

Schaie, K. W., \& Gribbon, K. (1975). Adult development and aging. Annual Review of Psychology, 26, 65-96.

Schaie, K. W., \& Hertzog, C. (1982). Longitudinal methods. In B. B. 
Woman (Ed.), Handbook of developmental psychology. Englewood Cliffs, NJ: Prentice Hall.

Schmidt, F. L., Hunter, J. E., Outerbridge, A. N., \& Goff, S. (1988). Joint relation of experience and ability with job performance: Test of three hypotheses. Journal of Applied Psychology, 73, 46-57.

Schmidt, F. L., Hunter, J. E., \& Pearlman, K. (1981). Task differences as moderators of aptitude test validity in selection: A red herring. Journal of Applied Psychology, 66, 166-184.

Schneider, W., \& Shiffrin, R. M. (1977). Controlled and automatic human information processing: I. Detection, search, and attention. Psychological Review, 84, 1-66.

Schwab, D. P., \& Heneman, H. G. (1977). Effects of age and experience on productivity. Industrial Gerontology, 4, 113-117.

Shiffrin, R. M., \& Schneider, W. (1977). Controlled and automatic human information processing: $\Pi$. Perceptual learning, automatic attending, and general theory. Psychological Review, 84, 127-190.

Simon, H. A., \& Chase, W. G. (1973). Skill in chess. American Scientist, 61, 394-403.

Snow, R. E., \& Lohman, D. F. (1984). Toward a theory of cognitive aptitude for learning from instruction. Journal of Educational Psychology, 76, 347-376.

Studdiford, W. A. (1951). A functional system of occupational classification. Occupations, 30, 37-42.
Taylor, J. G., \& Smith, P. C. (1956). An investigation of the shape of learning curves for industrial motor tasks. Journal of Applied Psychology, 40, 142-149.

Thorndike, E. L. (1908). The effect of practice in the case of a purely intellectual function. American Journal of Psychology, 19, 374-384.

Thorndike, E. L. (1914). Educational psychology (Vol. 3). New York: Columbia University Teachers College.

U.S. Department of Labor. (1977). Dictionary of occupational titles (4th ed.). Washington, DC: U.S. Government Printing Office.

U.S. Department of Labor. (1980). Manual for the USES General Aptitude Test Battery (Section II-A). Washington, DC: U.S. Employment Service, Employment and Training Administration, U.S. Department of Labor.

Viswesvaran, C., Ones, D. S., \& Schmidt, F. L. (1996). Comparative analysis of the reliability of job performance ratings. Journal of Applied Psychology, 8, 557-574.

Waldman, D. A., \& Avolio, B. J. (1986). A meta-analysis of age differences in job performance. Journal of Applied Psychology, 71, 33-38.

Woodrow, H. (1946). The ability to learn. Psychological Review, 53, $147-158$.

Received September 24, 1997

Revision received February 1, 2000

Accepted February 4, 2000

\section{New Editors Appointed, 2002-2007}

The Publications and Communications Board of the American Psychological Association announces the appointment of five new editors for 6-year terms beginning in 2002.

As of January 1, 2001, manuscripts should be directed as follows:

- For Behavioral Neuroscience, submit manuscripts to John F. Disterhoft, PhD, Department of Cell and Molecular Biology, Northwestern University Medical School, 303 E. Chicago Avenue, Chicago, IL 60611-3008.

- For the Journal of Experimental Psychology: Applied, submit manuscripts to Phillip L. Ackerman, PhD, Georgia Institute of Technology, School of Psychology, MC 0170, 274 5th Street, Atlanta, GA 30332-0170.

- For the Journal of Experimental Psychology: General, submit manuscripts to D. Stephen Lindsay, PhD, Department of Psychology, University of Victoria, P.O. Box 3050, Victoria, British Columbia, Canada V8W 3P5.

- For Neuropsychology, submit manuscripts to James T. Becker, PhD, Neuropsychology Research Program, 3501 Forbes Avenue, Suite 830, Pittsburgh, PA 15213.

- For Psychological Methods, submit manuscripts to Stephen G. West, PhD, Department of Psychology, Arizona State University, Tempe, AZ 85287-1104.

Manuscript submission patterns make the precise date of completion of the 2001 volumes uncertain. Current editors, Michela Gallagher, PhD; Raymond S. Nickerson, PhD; Nora S. Newcombe, PhD; Patricia B. Sutker, PhD; and Mark I. Appelbaum, PhD, respectively, will receive and consider manuscripts through December 31,2000. Should 2001 volumes be completed before that date, manuscripts will be redirected to the new editors for consideration in 2002 volumes. 